\title{
Dynamics and Functional Role of Dopaminergic Neurons in the Ventral Tegmental Area during Itch Processing
}

\author{
닌ei Yuan, ${ }^{1,2}$ Tong-Yu Liang, ${ }^{1,2}$ 이 Juan Deng, ${ }^{1}$ and $\odot$ Yan-Gang Sun ${ }^{1}$ \\ ${ }^{1}$ Institute of Neuroscience, State Key Laboratory of Neuroscience, Center for Excellence in Brain Science and Intelligence Technology, Chinese Academy of \\ Sciences, Shanghai 200031, People's Republic of China, and 'University of Chinese Academy of Sciences, Beijing 100049, People's Republic of China
}

Itchiness triggers a strong urge to engage in scratching behavior, which could lead to severe skin or tissue damage in patients with chronic itch. This process is dynamically modulated. However, the neural mechanisms underlying itch modulation remain largely unknown. Here, we report that dopaminergic (DA) neurons in the ventral tegmental area (VTA) play a critical role in modulating itch-induced scratching behavior. We found that the activity of VTA DA neurons was increased during pruritogen-induced scratching behavior in freely moving male mice. Consistently, individual VTA DA neurons mainly exhibited elevated neural activity during itch-induced scratching behavior as demonstrated by in vivo extracellular recording. In behavioral experiments, the transient suppression of VTA DA neurons with the optogenetic approach shortened the pruritogen-induced scratching train. Furthermore, the DA projection from the VTA to the lateral shell of the nucleus accumbens exhibited strong activation as measured with fiber photometry during itch-elicited scratching behavior. These results revealed the dynamic activity of VTA DA neurons during itch processing and demonstrated the modulatory role of the DA system in itch-induced scratching behavior.

Key words: dopaminergic; itch; modulation; scratching

\section{Significance Statement}

Itchiness is an unpleasant sensation that evokes a scratching response for relief. However, the neural mechanism underlying the modulation of itch-evoked scratching in the brain remains elusive. Here, by combining fiber photometry, extracellular recording, and optogenetic manipulation, we show that the dopaminergic neurons in the ventral tegmental area play a modulatory role in itch-evoked scratching behavior. These results reveal a potential target for suppressing excessive scratching responses in patients with chronic itch.

\section{Introduction}

Itch is an unpleasant sensation that evokes the desire to scratch. Recent studies have begun to reveal the brain mechanism of itch processing (Mu et al., 2017; Yu et al., 2017; Dong and Dong, 2018). It was shown that the parabrachial nucleus represents a central relay for itch signal transmission (Mu et al., 2017), and the suprachiasmatic nucleus of the hypothalamus participates in contagious itch (Yu et al., 2017). In addition, many other brain areas, including the anterior cingulate cortex (ACC), insular cor-

\footnotetext{
Received June 11, 2018; revised Sept. 10, 2018; accepted Sept. 14, 2018.

Author contributions: L.Y. and Y.-G.S. designed research; L.Y., T.-Y.L., and J.D. performed research; L.Y., J.D., and Y.-G.S. analyzed data; L.Y. and Y.-G.S. wrote the paper.

This work was supported by the National Natural Science Foundation of China (Grants 31771158 and 31371122) and the Strategic Priority Research Program of the Chinese Academy of Sciences (Grant XDBS01000000). We thank Yanjing Zhu, Qing Li, and Di Mu for technical support. We also thank Yong Gu, He Cui, and all members of the Y.-G.S. laboratory for helpful discussion.

The authors declare no competing financial interests.

Correspondence should be address to Dr. Yan-Gang Sun, Institute of Neuroscience, Chinese Academy of Sciences, 320 Yue Yang Road, Shanghai, People's Republic of China, 200031. E-mail: yangang.sun@ion.ac.cn.

https://doi.org/10.1523/JNEUROSCl.1483-18.2018

Copyright $\odot 2018$ the authors $\quad 0270-6474 / 18 / 389856-14 \$ 15.00 / 0$
}

tex, ventral tegmental area (VTA), and amygdala, exhibited activity changes relevant to itch stimuli as shown in human brainimaging studies (Herde et al., 2007; Leknes et al., 2007; Papoiu et al., 2013). Some of these brain areas could also play important roles in itch modulation, as evidenced by a recent study showing that the ACC modulates histaminergic itch processing (Lu et al., 2018).

Sensory information processing is dynamically modulated by the neuromodulatory system (Kupfermann, 1979; HarrisWarrick and Marder, 1991), which also regulates itch processing. Serotoninergic neurons in the brainstem send descending projections to the spinal cord and facilitate itch transmission by releasing serotonin and activating HTR1A and gastrin-releasing peptide receptors (Zhao et al., 2014). The endogenous release of noradrenaline at the spinal level has also been shown to facilitate the itch-evoked scratching response via $\alpha$-adrenoceptors (Gotoh et al., 2011a,b). In addition, previous pharmacological studies have demonstrated the functional involvement of the dopaminergic (DA) system in itch processing in both rodents and primates. Blocking dopamine $\mathrm{D}_{1}$ receptors decreased scratching 
behavior induced by compound 48/80 in mice (Akimoto and Furuse, 2011), suggesting that the activation of dopamine $D_{1}$ receptors might promote scratching behavior. Interestingly, studies in monkeys have shown that the activation of dopamine $D_{2}$ receptors, but not $D_{1}$ receptors, induced scratching behavior (Rosenzweig-Lipson et al., 1994; Pellón et al., 1995). DA neurons are mainly located in the substantia nigra pars compacta $(\mathrm{SNc})$ and VTA. However, the precise dynamics and functional role of DA neurons in itch processing still remain elusive.

DA neurons in the VTA are well known to encode value teaching signals in learning (Schultz et al., 1997; Schultz, 2006; Bromberg-Martin et al., 2010; Cohen et al., 2012; Matsumoto et al., 2016) and have been implicated in seeking relief from aversive sensory states, including pain. VTA DA neurons have been shown to be essential for the acquisition of a behavioral preference for an environment associated with pain relief (Navratilova et al., 2015). Although the VTA exhibits activity significantly correlated with scratching-induced pleasure (Papoiu et al., 2013), whether DA neurons in the VTA are involved in modulating scratching behavior to relieve itchiness, which also represents an aversive sensation state, remains unclear. Thus, we examined the temporal dynamics of DA neurons in the VTA with fiber photometry and in vivo extracellular recording in freely moving animals and characterized the functional role of VTA DA neurons in itch-induced scratching behavior by manipulating their activity with optogenetics.

\section{Materials and Methods}

\section{Animals}

Dopamine transporter (DAT)::IRES-Cre knock-in mice (JAX006660; hereafter referred as DAT-Cre mice) were obtained from The Jackson Laboratory and crossed with wild-type C57BL/6J mice. Only male heterozygous DAT-Cre mice were used in our experiments. Mice 8-10 weeks of age received virus injections for the photometry recording and behavioral test. Mice 10-12 weeks of age received virus injections to identify the DA neurons in vivo in the VTA. Mice 4 weeks of age received virus injections for the slice electrophysiological recording. All mice were housed under stable conditions with ad libitum access to food and water under a $12 \mathrm{~h}$ light/dark cycle (lights on from 7:00 A.M. to 7:00 P.M.). All animal studies and experimental procedures were approved by the Animal Care and Use Committee of the Institute of Neuroscience, Chinese Academy of Sciences.

\section{Surgeries for viral delivery and optic fiber and} electrode implantation

General surgical procedures and viral delivery. Before the surgical procedures, the mice were anesthetized with $1 \%$ pentobarbital sodium (dissolved in saline; injection dose, $100 \mathrm{mg} / \mathrm{kg}$, i.p.), the back of their necks were shaved for the delivery of pruritogens, and a magnet $(1 \mathrm{~mm}$ in diameter, $3 \mathrm{~mm}$ in length) was implanted into the right hindpaw to record scratching behavior. Then, the mice were placed on a stereotaxic frame (Stoelting), and surgery was performed as previously described (Cetin et al., 2006). To specifically express the viral constructs in VTA DA neurons, recombinant adeno-associated viruses (AAVs) were injected into the VTA [relative to bregma: anteroposterior (AP), $-3.35 \mathrm{~mm}$; mediolateral (ML), $0.45 \mathrm{~mm}$; dorsoventral (DV), $-4.25 \mathrm{~mm}$ ] of DATCre mice. The virus was injected with a glass pipette (tip diameter, $20 \sim 30$ $\mu \mathrm{m})$ at a rate of $0.05-0.1 \mu \mathrm{l} / \mathrm{min}(0.25-0.4 \mu \mathrm{l} / \mathrm{site})$. The virus was infused unilaterally for the fiber photometry and identification of DA neurons in the optrode recording. For the slice electrophysiological recording and optogenetic inhibition of DA neurons during the behavioral test, the virus was injected into the VTA bilaterally.

Viral constructs. For the photometry recording, Cre-dependent AAV vectors carrying fluorescent calcium indicator GCaMP6s [AAV-hSynDIO-GCaMP6s, $4.5 \times 10^{12}$ genome copies $(\mathrm{gc}) / \mathrm{ml}$ ] or control (AAVEf1 $\alpha$-DIO-EYFP, $5.54 \times 10^{12} \mathrm{gc} / \mathrm{ml}$ ) were serotyped with AAV5 or
AAV9 coat proteins and packaged by Shanghai Taitool Bioscience Co. Ltd. To identify the DA neurons in vivo, the transgene [AAV-Efl $\alpha$-DIOChR2 (H134R)-mCherry, $5.2 \times 10^{12} \mathrm{gc} / \mathrm{ml}$; packaged by Vector Core at the University of North Carolina at Chapel Hill (UNC Vector Core), Chapel Hill, NC] was serotyped with AAV5 coat proteins. The transgenes used for the optogenetic inhibition (AAV-CAG-DIO-GtACR1-EGFP, $4.5 \times 10^{12} \mathrm{gc} / \mathrm{ml}$; packaged by Shanghai Taitool Bioscience Co. Ltd) or control (AAV-Ef1 $\alpha$-DIO-EYFP, $4.4 \times 10^{12} \mathrm{gc} / \mathrm{ml}$; packaged by UNC Vector Core) were serotyped with AAV5 coat proteins.

Optic fiber implantation (for the fiber photometry and optogenetic experiments). Following the AAV infusion, an optic fiber [diameter, $200 \mu \mathrm{m}$; numerical aperture (NA), 0.37] was immediately implanted into the VTA (AP, $-3.35 \mathrm{~mm}$; ML, $0.4 \mathrm{~mm}$; DV, $-4.20 \mathrm{~mm}$ ), nucleus accumbens (NAc) lateral shell (LaSh; AP, $0.98 \mathrm{~mm}$; ML, $1.75 \mathrm{~mm}$; DV, $-4.6 \mathrm{~mm}$ ) or NAc medial shell (MeSh; AP, $1.54 \mathrm{~mm}$; ML, $0.5 \mathrm{~mm}$; DV, $-4.5 \mathrm{~mm}$ ) for the fiber photometry recording. To optogenetically inhibit VTA DA neurons during scratching, the optic fibers were implanted bilaterally above the VTA at the angle of 10 degrees (AP, $-3.4 \mathrm{~mm}$; ML, $1.25 \mathrm{~mm}$; DV, $-4.1 \mathrm{~mm}$ ). A thin layer of tissue gel (Kwik-Cast Sealant) was added to the surgical hole to prevent contact between the dental cement and brain tissue. Then, gel (Vetbond Adhesive, $3 \mathrm{M}$ ) was applied to the skull surface, and a thin layer of dental cement was immediately applied to the skull surface. A thick layer of dental cement was applied to build a head cap and cover the skull surface.

Electrode implantation for the extracellular recording. The electrode was homemade by using a screw-driven Microdrive, as previously described (Liu et al., 2014). Briefly, 12 16 Ni-Chrome microwires (diameter, 33 $\mu \mathrm{m} /$ wire; California Fine Wire Co) were glued to a polyimide guide tube (inner diameter, $250 \mu \mathrm{m}$; outer diameter, $355 \mu \mathrm{m}$ ). To identify the DA neurons by light stimulation, an extra optic fiber was added (diameter, $200 \mu \mathrm{m}$; NA, 0.37) to the guide tube, and the end of the optic fiber was 200 400 $\mu \mathrm{m}$ shorter than the ends of the microwires. The microwire array was inserted into the microdrive chamber and glued to a movable screw nut. The wire tips on one side were soldered to corresponding pins on a printed circuit board (PCB) connector. The wire tips on the other side were electroplated to a final impedance of $\sim 1.5 \mathrm{M} \Omega$ after the assembly of the electrode. The electrode with the optic fiber was referred to as an optrode. The optrode was implanted into the VTA (AP, $-3.35 \mathrm{~mm}$; ML, $0.4 \mathrm{~mm}$; DV, $-4.0 \mathrm{~mm}$ ) of DAT-Cre animals, which were injected with AAV expressing channelrhodopsin 2 (ChR2) at least 3 weeks before the implantation. The ground and reference wires were separately soldered to the corresponding pins on the PCB on one side and to two skull-mounted cranial screws on the other side. Then, dental cement was carefully applied as described for the optic fiber implantation, except that the cement did not contact the microwires, allowing for the wires to be lowered after the surgery.

\section{Scratching behavior induction and recording}

The mice were handled gently and habituated to the recording barrel before any recording or behavioral test for at least $2 \mathrm{~d}$. On the test day, the mice were first habituated to the recording barrel for at least $15 \mathrm{~min}$. Scratching behavior was acutely induced by an intradermal injection of chloroquine $(200 \mu \mathrm{g} / 50 \mu \mathrm{l}$; catalog \#C6628-25G, Sigma-Aldrich) or endothelin-1 (25 ng/50 $\mu \mathrm{l}$; catalog \#1160, Tocris Bioscience). The behavior-recording system and magnetic induction method were custom made following established methods (Inagaki et al., 2002; Mu et al., 2017). Briefly, a transparent, cylindrical recording barrel (diameter, 15 $\mathrm{cm}$; height, $20 \mathrm{~cm}$ ) was surrounded by a coil of wire (Fig. $1 \mathrm{~A}$ ). The movement (including general movement and scratching) of the magnet implanted into the right hindpaw of the mice in the barrel induced a small voltage change that was sent to an analog channel in the fiber photometry or extracellular recording system and recorded at 1000 and $2000 \mathrm{~Hz}$ separately. During the optogenetic behavioral test, the voltage change was recorded by a custom-written MATLAB code at $2000 \mathrm{~Hz}$.

\section{Fiber photometry}

Recording VTA dopaminergic neuron population activity during scratching behavior. DAT-Cre mice were injected with virus expressing GCaMP6s or enhance yellow fluorescent protein (EYFP), and an optic fiber was 
implanted into the VTA or NAc to record VTA DA neuron population activity or projection activity during scratching behavior. The animals were allowed to recover after surgery for at least $10 \mathrm{~d}$ before recording the DA population activity in the VTA or 3 weeks before recording the DA projection activity. The mice were handled gently for $3 \mathrm{~min}$ and then habituated to the recording barrel, while the implanted optic fiber was connected to a patch cord for 30 min daily for at least $2 \mathrm{~d}$. During the recording, the mouse scratching behavior and fluorescence signal were simultaneously recorded at $1000 \mathrm{~Hz}$ with F-scope-G-2 (BioLink Optics) for $30 \sim 40 \mathrm{~min}$ after the delivery of pruritogens. The laser power at the tip of the implanted optic fiber was $\sim 15 \mu \mathrm{W}$. After the recording, the system noise was collected for $10 \mathrm{~s}$ while any visual input to the recording optic fiber was physically prevented. The data were transformed into an MAT file and analyzed using a custom-written MATLAB code.

Recording VTA dopaminergic neuron population activity during manual scratching nape. VTA ${ }^{\text {DA-GCaMP6s }}$ mice were placed on a towel and habituated for $3 \mathrm{~min}$ while the implanted optic fiber was connected to an external patch cord. The nape of the mice was scratched by the experimenter using pointed metal tweezers in one direction at $\sim 2 \mathrm{~Hz}$ for 20 strokes at an interval of $\sim 60 \mathrm{~s}$. The manual scratching left light-visible grooves on the nape that disappeared within a few seconds. The start time of the scratching was recorded with Master 9 amplifier connected to the fiber photometry system. In a few trials, the tested mice moved during the manual scratching (which might have caused motion artifacts), and these trials were marked and excluded from further analysis.

Recording VTA dopaminergic neuron population activity while running on a rotarod. VTA ${ }^{\mathrm{DA}-\mathrm{GCaMP} 6 \mathrm{~s}}$ mice were trained to walk while maintaining balance on a rotarod apparatus (Ugo Basile) that rotated at a constant speed for 5 min on day 1 . Each mouse was subjected to three training sessions in which the rod rotated at 5,10 , or $20 \mathrm{rpm}$ with an intersession interval $>60 \mathrm{~min}$. Then, the mice were returned to their home cages. On day 2 , the mice were placed on a nonrotating rod for $30 \mathrm{~s}$, and the implanted optic fiber was connected to an external patch cord. The baseline fluorescence of the DA neuron population was recorded for $\sim 60 \mathrm{~s}$. Then, the rod accelerated to $20 \mathrm{rpm}$ within $3 \mathrm{~s}$ and rotated for a maximum duration of $300 \mathrm{~s}$. The time when the rod started to accelerate was manually recorded with Master 9 connected to the fiber photometry system.

In vivo electrophysiology

The mice were allowed to recover for $7 \mathrm{~d}$ after the optrode implantation surgery. The mice were handled gently for $3 \mathrm{~min}$ and then habituated to the recording barrel, while the implanted electrode was connected to the external head stage for at least $30 \mathrm{~min}$ daily for at least $2 \mathrm{~d}$ before the subsequent recording. For the extracellular recording, the signals from each wire were bandpass filtered between 250 and $5000 \mathrm{~Hz}$ with CerePlex Direct (Blackrock Microsystems). Spikes were detected and recorded by manually setting the signal threshold (usually $>2.5$ times of the root mean square of the noise) after subtracting the signal from the reference wire from which no spike signals were recorded to decrease the motion noise. All data were saved to a hard drive for further analysis.

In the daily recordings, the DA neurons were first targeted using optogenetics to observe light stimulation-induced spikes. Laser illumination was provided by a blue $(473 \mathrm{~nm})$ diode-pumped solid-state laser controlled by Master 9 . Trains of 10 light pulses at 1,10 , or $20 \mathrm{~Hz}(5 \mathrm{~ms}$, 1-12 mW) were delivered. In each test, in total, 200 or 300 pulses were
B

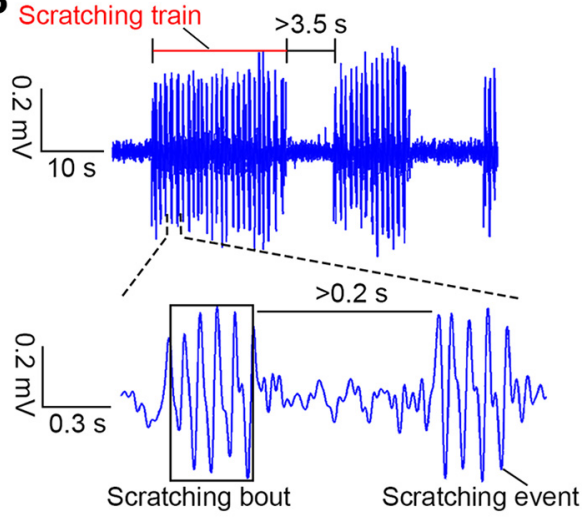

Figure 1. Recording and definition of scratching behavior. $\boldsymbol{A}$, Schematic of the recording of scratching behavior. $\boldsymbol{B}$, Example trace including scratching behavior. Top, A 60 s trace; bottom, a 1.7 s trace, including two scratching bouts. $C$, Example showing a false identified scratching bout, indicated by the dashed black box.

delivered. To identify the DA neurons, the following two criteria were used (Cohen et al., 2012): (1) the $p$ value determined by the stimulusassociated spike latency test (Pi et al., 2013) was $<0.001$, suggesting that significant changes in the spike timing occurred due to the light pulses and activation after light onset; and (2) the Pearson correlation coefficient between the light-induced waveforms and spontaneous waveforms was $>0.9$ to rule out the possibility of light-induced contamination. The light intensity was decreased if the induced spike waveforms were deformed compared with the spontaneous spike waveforms, possibly due to high intensities (Cohen et al., 2012). To test whether the neurons were directly activated by the light stimulation, spikes were detected within the first $10 \mathrm{~ms}$ after light onset. The latency of light activation was defined by the delay of the first spike within the detection period, and its jitter was calculated.

If DA neurons were identified, their activities and chloroquineinduced scratching behavior (sampled at $2000 \mathrm{~Hz}$ ) were simultaneously recorded for $40 \mathrm{~min}$. The electrodes were lowered by $\sim 65 \mu \mathrm{m}$ daily by turning the screw $\sim 90^{\circ}$ after the recording or that no neurons were activated by light. Electrolytic lesions were created using $8 \mathrm{~s}$ of $25 \mu \mathrm{A}$ direct currents after the final recording immediately before perfusion.

\section{Slice electrophysiology}

To test the efficiency of the inhibition of the DA neurons by optogenetics, 1-month-old DAT-Cre mice were infused with AAV-DIO-GtACR1EGFP or AAV-DIO-EYFP virus in the VTA, and slice electrophysiology was performed 2 weeks after the viral infusion, as previously described (Zhou et al., 2017). The mice were perfused with ice-cold cutting solution containing the following (in $\mathrm{mm}$ ): sucrose 213, $\mathrm{KCl} 2.5, \mathrm{NaH}_{2} \mathrm{PO}_{4} 1.25$, $\mathrm{MgSO}_{4} 10, \mathrm{CaCl}_{2} 0.5, \mathrm{NaHCO}_{3} 26$, and glucose 11 (300-305 mOsm) after being anesthetized with isoflurane (Lunan Pharmaceutical). The mouse brains were dissected, and coronal slices $(220 \mu \mathrm{m})$ were prepared in ice-cold cutting solution using a vibratome (model VT1200S, Leica) at a speed of $0.12 \mathrm{~mm} / \mathrm{s}$ and a blade vibration amplitude of $0.08 \mathrm{~mm}$. Brain slices containing the VTA were transferred to a holding chamber and 
incubated with artificial CSF (ACSF) containing the following (in $\mathrm{mm}$ ): $\mathrm{NaCl} 126, \mathrm{KCl} 2.5, \mathrm{NaH}_{2} \mathrm{PO}_{4} 1.25, \mathrm{MgCl}_{2} 2, \mathrm{CaCl}_{2} 2, \mathrm{NaHCO}_{3} 26$, and glucose $10(300-305 \mathrm{mOsm})$ at $34^{\circ} \mathrm{C}$ to recover for $30 \mathrm{~min}$. Then, the slices were kept at room temperature before the recording. The cutting solution and ACSF were continuously bubbled with $95 \% \mathrm{O}_{2}$ and $5 \%$ $\mathrm{CO}_{2}$. The slices were placed on poly-L-lysine (Sigma-Aldrich)-coated glass and submerged in a recording chamber (Warner Instruments) perfused with ACSF at 3-4 ml/min using a pump (model BT100-2J, Longer Precision Pump Co.). All experiments were performed at room temperature $\left(25-28^{\circ} \mathrm{C}\right)$

To verify the functional efficiency of AAV-DIO-GtACR1-EGFP in inhibiting VTA DA neurons, GtACR ${ }^{+}{ }^{+}$neurons in the VTA were recorded in the current-clamp mode with a potassium-based internal solution containing the following (in $\mathrm{mM}$ ): K-gluconate $130, \mathrm{MgCl}_{2} 1, \mathrm{CaCl}_{2} 1$, KCl 1, HEPES 10, EGTA 11, Mg-ATP 2, and Na-GTP 0.3 (pH 7.3, 290 $\mathrm{mOsm}$ ). Action potentials were induced by injecting $100 \mathrm{pA}$ currents for $1.5 \mathrm{~s}$, and a blue laser $(473 \mathrm{~nm}, 10 \mathrm{~mW})$ was delivered for $0.5 \mathrm{~s}$ to activate GtACR1 $0.5 \mathrm{~s}$ after the current injection initiation. The firing rates during the $0.5 \mathrm{~s}$ before the light delivery (baseline period) and the light stimulation period were analyzed using Igor Pro (WaveMetrics) and compared to quantify the inhibition of GtACR1 ${ }^{+}$neurons using Prism 6 (GraphPad Software). The control experiment for the $\mathrm{EYFP}^{+}$neurons in AAVDIO-EYFP virus-injected mice was performed and analyzed as described for the GtACR1 group.

\section{Behavioral experiments}

Optogenetic inhibition in itch behavior test. The mice were allowed to recover after surgery for 4 weeks and then were habituated to the recording barrel, while the implanted optic fiber was connected to a patch cord for $30 \mathrm{~min}$ daily for 1 week. On the test day, scratching behavior was evoked by an intradermal injection of chloroquine and recorded. To temporally manipulate VTA DA neurons during scratching behavior, a custom MATLAB code was written to simultaneously record the animal behavior and control the delivery of light through Master 9. To test the necessity of the temporal activation of the DA neuron population for the ongoing scratching behavior, behavior traces were manually monitored in real time, and a constant blue laser $(473 \mathrm{~nm})$ was delivered for $3 \mathrm{~s}$ once a scratching train was initiated. If the scratching train did not stop or a new scratching bout appeared, another light was manually delivered for $3 \mathrm{~s}$ until the train ended. The light was supplied at $7 \mathrm{~mW}$ at the tip of an implanted optic fiber by a blue diode-pumped solid-state laser. The light delivery timing and scratching behavior were simultaneously recorded.

To test whether scratching behavior is affected by the pseudorandom photoinhibition of DA neurons, GtACR1 and EYFP mice were manipulated in pairs. For each pair of GtACR1 and EYFP mice, light was delivered simultaneously to both mice according to the scratching behavior of the EYFP mouse regardless of whether the GtACR1 mouse was scratching or not.

Open field test. To test the effect of the transient optogenetic inhibition of VTA DA neurons on the subject's locomotor behavior, $473 \mathrm{~nm}$ light was delivered at $7 \mathrm{~mW}$ at randomly selected times ( 29 times, $3 \mathrm{~s}$ each time), and the same pattern was used in all mice during the open field test. The mice were placed in the center of an open field box $(40 \times 40 \times$ $40 \mathrm{~cm}$ ) and videotaped by a camera positioned above the box for $10 \mathrm{~min}$. The moving track was recorded and analyzed by LabState software (AniLab).

\section{Data analysis}

Scratching behavior analysis. Motion (including both moving and scratching) induced large voltage fluctuations (defined as voltage peaks). The moving signals and scratching signals exhibited different characteristics as follows: each moving signal contained a single voltage peak (defined as a motion event), while scratching induced a cluster of voltage peaks (each peak during scratching was defined as a scratching event). Moreover, some scratching events were closer to each other, and a cluster of adjacent scratching events was defined as a scratching bout. A cluster of adjacent scratching bouts was defined as a scratching train. To strictly define scratching events, scratching bouts, and scratching trains, the threshold of the voltage peak was calculated by one-eighth of the value generated by the MATLAB function thselect (adaptive threshold selection using the principle of Stein's unbiased risk estimate) for each behavioral trace. Scratching bouts were defined as a cluster of peaks (including at least two consecutive peaks) with an interpeak interval of $<0.2 \mathrm{~s}$ (the frequency of scratching events in a scratching bout greatly varied between $\sim 5$ and $45 \mathrm{~Hz}$ by a manual analysis of the scratching traces). Scratching trains were defined as a cluster of scratching bouts with an interbout interval of $<3.5 \mathrm{~s}$ (Fig. $1 B$ ). Other peaks above the threshold were considered as other motion events (Fig. $1 C$ ). Then, the result was manually adjusted by a customized graphical user interface program to detect missed scratching events and to delete false scratching events (Fig. $1 D)$. For the behavioral experiments, the number of scratching bouts/ trains and the average duration of scratching bouts/trains were calculated.

Fiber photometry data processing and analysis. First, the fluorescence values were low-pass filtered at $2 \mathrm{~Hz}$ using a fourth-order Butterworth filter with zero phase distortion. The scratching train onset was identified as mentioned above. Then, the noise signal of the recording system was subtracted from the fluorescence values, and the resulting values were aligned to the scratching train onset. The fluorescence values during each scratching train were derived. The change in the fluorescence values in each scratch train was calculated as follows:

$$
\Delta F / F=\left(F-F_{0}\right) / F_{0},
$$

where $F$ refers to the fluorescence values at each time point $(-3.5$ to $5 \mathrm{~s}$ relative to the scratching train onset), and $F_{0}$ refers to the median of the fluorescence values during the baseline period $(-2.2$ to $-1 \mathrm{~s}$ relative to the scratching train onset). To visualize the fluorescence change, the $\Delta F / F$ values of each scratching train were heat plotted for each mouse and averaged. To statistically quantify the change in fluorescence values across scratching train onsets, the onset period was defined as $0.5-1.2 \mathrm{~s}$ relative to the scratching train onset. To quantify the change in the DA fluorescence values across noxious stimuli (manual scratching), the baseline period $(-2.2$ to $-1 \mathrm{~s}$ relative to the stimuli onset), and the onset period (1-3 s relative to the stimuli onset) were defined. To quantify the change in the DA fluorescence values while running on a rotarod, the baseline period ( -30 to $0 \mathrm{~s}$ relative to running onset) and running period $(0-30$ s relative to onset $)$ were defined. The average fluorescence changes in each window were calculated and compared.

In vivo electrophysiology. Spike sorting was performed based on the waveform features (peaks and valleys) and principal components using Offline Sorter software. A single unit was included only if there were not $>0.5 \%$ of spikes within a $2 \mathrm{~ms}$ refractory period. The cluster quality was quantified using the L-ratio (Harris et al., 2001; Schmitzer-Torbert et al., 2005) and isolation distance (Harris et al., 2001). Clusters with L-ratios $<0.05$ or an isolation distance $>50$ were used in further analyses. To guarantee that independent units were recorded on different days, units resembling previous units recorded on the same wire were not included. Neurons with stable recording after itch induction met the following two criteria: (1) the correlation coefficient between the average waveforms during light identification and those during the behavioral recording was $>0.9$; and (2) action potentials fired at least until $5 \mathrm{~min}$ before the end of the recording (the mice barely scratched during the final $5 \mathrm{~min}$ ). These neurons were included in the subsequent analysis.

Further analysis was performed using custom-written codes in MATLAB. To calculate the firing rates, peristimulus time histograms (PSTHs) of the scratching train onset of each neuron were constructed using $10 \mathrm{~ms}$ bins. To characterize the responses at the population level, we used a receiver operating characteristic (ROC) analysis as previously described (Cohen et al., 2012). Briefly, to calculate the spike density distribution, PSTHs were convolved with a $10 \mathrm{~ms}$ Gaussian kernel and converted to $100 \mathrm{~ms}$ bins. Similarly, the baseline period was defined as -2.8 to $-1.6 \mathrm{~s}$ before the scratching train onset. We compared the distribution of the spike firing rates in each time bin $(t 1)$ after the baseline period ( -1.6 to $5 \mathrm{~s}$ relative to the scratching train onset) to that in all bins $(t 0)$ during the baseline period across all scratching trains by moving the criterion from 0 to the maximum firing rate in all bins of each neuron. The ROC curve of each $t 1$ bin was obtained by plotting the probability 
that the firing rate during $t 1$ was greater than the criteria against the probability that the firing rate during to was greater than the criteria. The area under the curve (AUC) quantifies the overlapping degree between the two spike firing rate distributions, and an AUC of $>0.5$ indicates an increase in the firing rate relative that at baseline, whereas an AUC of $<0.5$ indicates a decrease. The AUC ROC response profiles of all neurons were obtained. To visualize the population response profile, the AUC ROC were sorted by the mean values from 0 to $0.6 \mathrm{~s}$ after the scratching train onset and plotted as a heat map using "Jet" color map for each neuron in MATLAB.

To statistically analyze the firing rate changes in individual DA neurons across the entire scratching train, the following two time windows were defined: baseline window $(-2.8$ to $-1.6 \mathrm{~s}$ relative to the scratching train onset) and scratching train window (entire scratching train). The average firing rate in each time window was calculated for each scratching train. The significance of the activity change in each neuron during the scratching train was determined by paired $t$ test. The average firing rates of each neuron across all scratching trains in each time window were considered the averaged activities before and during the scratching train. To statistically test the change in DA neuron population activity during a scratching train, we performed a Wilcoxon matched-pairs signed rank test.

To statistically analyze the neural responses to the scratching train onset at the single-neuron level, the following two time windows were defined: baseline window $(-2.8$ to $-1.6 \mathrm{~s}$ relative to the scratching train onset) and scratching train onset period $(0-0.6 \mathrm{~s}$ relative to the scratching train onset). The fractional changes in the average firing rate during the onset period were calculated for all scratching trains, and the significance of the changes was determined by their percentile within a nonparametric bootstrap distribution estimated by 500 random circular permutations of spike timing relative to the scratching train onset (Tye et al., 2013). We found that 12 neurons showed a significant response during the onset period. To analyze the response latency in these 12 neurons, smoothed $10 \mathrm{~ms}$ bin PSTHs were used. The average and SD of the firing rates during the baseline period were calculated across scratching trains, and the response latency was defined as the first bin in which the average firing rates were above (or below) the mean plus (or minus) three times the SD after the baseline period.

To analyze the response of DA neurons to general motion, the voltage peaks of the behavioral trace were identified as described in the Scratching behavior analysis section, and general motion-related events (called other motion events, including general movement and climbing on the recording barrel wall) were found after excluding the scratching-related peaks. If the number of other motion-related events was $>120,60$ events were randomly selected as motion events for subsequent analysis. If the number of motion-related events was $<120$, half of the events were randomly selected. The response of the DA neurons to the resulting other motion events was analyzed and visualized similarly to the scratching train events.

\section{Histology}

Perfusion. The mice were anesthetized with an overdose of $1 \%$ pentobarbital sodium and perfused with saline, followed by 4\% PFA (SigmaAldrich) in $0.01 \mathrm{M}$ PBS. The brains were carefully removed and postfixed in $4 \%$ PFA for an additional $4 \mathrm{~h}$; then, the brains were kept in a $30 \%$ sucrose solution in $0.01 \mathrm{M} \mathrm{PBS}$ at $4^{\circ} \mathrm{C}$ for at least $2 \mathrm{~d}$.

Immunofluorescence staining. Free-floating coronal sections $(40 \mu \mathrm{m})$ prepared with a cryostat (model CM 1950, Leica) were used for the immunofluorescent staining. The brain sections were blocked for $30 \mathrm{~min}$ at room temperature in $5 \%$ normal donkey serum in PBST $(0.3 \%$ Triton $\mathrm{X}-100$ in $0.01 \mathrm{M}$ PBS), followed by incubation with primary antibodies in PBST (with $1 \%$ normal donkey serum) at $4^{\circ} \mathrm{C}$ overnight and secondary antibodies in PBST (with $0.5 \mu \mathrm{g} / \mathrm{ml}$ DAPI) at room temperature for $2.5 \mathrm{~h}$. Photomicrographs of the brain sections were taken using a Nikon E80i fluorescence microscope, an Olympus VS120 microscope, and a Nikon E600FN Neurolucida microscope $(10 \times)$, and confocal images of the VTA area were taken using a Nikon NiE-A1 plus confocal microscope $(40 \times)$.
For the immunofluorescence staining to identify the expression specificity of ChR2 in light-identifying DA neurons, the primary antibodies included mouse anti-tyrosine hydroxylase (TH; 1:1000; catalog \#22941, ImmunoStar; RRID:AB_572268) and rabbit anti-DsRed (1:500; catalog \#632496, Clontech; RRID:AB_10013483), while the secondary antibodies included Alexa Fluor 488-donkey anti-mouse (1:400; catalog \#715-545-150, Jackson ImmunoResearch; RRID:AB_2340846) and Cy3donkey anti-rabbit (1:400; catalog \#711-165-152, Jackson ImmunoResearch; RRID:AB_2307443). To identify the expression specificity of GCaMP6s or GtACR1, the primary antibodies included mouse antityrosine hydroxylase (1:1000; ImmunoStar) and rabbit anti-GFP (1:500; catalog \#A11122, Life Technologies), while the secondary antibodies included Cy3-donkey anti-mouse (1:400; catalog \#715-165-150, Jackson ImmunoResearch; RRID:AB_2340813) and Alexa Fluor 488-donkey anti-rabbit (1:400; catalog \#711-545-152, Jackson ImmunoResearch; RRID:AB_2313584). To identify the expression of GCaMP6s or GtACR1, the primary antibody was rabbit anti-GFP (1:500; Life Technologies), and the secondary antibody was Alexa Fluor 488-donkey anti-rabbit (1: 400; Jackson ImmunoResearch).

Identifying the specificity of GCaMP6s, ChR2, and GtACR1 expression in dopaminergic neurons. To determine whether GCaMP6s, ChR2, and GtACR1 are selectively expressed in DA neurons, we captured confocal images (40×; NiE-A1 Plus Confocal Microscope, Nikon) of randomly selected brain regions in the VTA from approximately two to three sections randomly selected from each mouse $(n=3)$ transduced with the Cre-dependent GCaMP6s, ChR2, or GtACR1 protein. The number of cells expressing GCaMP6s, ChR2, GtACR1, or tyrosine hydroxylase, which is a DA neuron marker, was counted in ImageJ software (NIH).

\section{Experimental design and statistical analysis}

The sample size of each experiment is provided in the Results. The data are expressed as the mean \pm SEM. The statistical analyses were performed using Prism 6 and MATLAB 2013b (MathWorks), and the confidence level was set to 0.05. $p$ Values $<0.001$ are reported as $p<0.001$, and all statistical parameters are reported in the Results. Paired $t$ tests and Wilcoxon matched-pairs signed rank tests were used for the paired value comparisons in the fiber photometry, extracellular recording, and slice electrophysiology. Two-way repeated-measures ANOVA, followed by analysis with a post hoc Bonferroni's test, was used to perform the fluorescence change comparisons between the GCaMP6s and EYFP groups with multiple fiber photometry recording measurements. Nonparametric bootstrapping was used to test the significance of the firing rate change in single neurons during scratching train onset. Unpaired $t$ test was used to compare for the DA projection fluorescence changes among different subregions in the fiber photometry and behavioral analyses.

\section{Results}

\section{Activity of VTA DA neuron population is correlated with itch-induced scratching behavior}

We examined the activity of the VTA DA neuron population by measuring the bulk calcium-related fluorescent signal using fiber photometry (Gunaydin et al., 2014). To target the VTA DA neurons, we injected a Cre-dependent AAV encoding the fluorescent calcium indicator GCaMP6s (AAV-hSyn-DIO-GCaMP6s) unilaterally into the VTA of transgenic mice expressing Cre recombinase under the control of the promoter of the DAT gene (also called Slc6a3; Fig. 2A), hereafter referred to as VTA DA-GCaMP6s mice. The control animals were injected with a Cre-dependent virus encoding EYFP (AAV-EF1 $\alpha$-DIO-EYFP). Optic fibers were implanted into the viral injection sites for the subsequent collection of the fluorescent signal of GCaMP6s/EYFP (Fig. 2A-C). We quantified the specificity and efficiency of the GCaMP6s expression in the VTA and found that $94.7 \%$ of neurons (179 of 189) expressing GCaMP6s were labeled with $\mathrm{TH}$, which is a marker of DA neurons, and $86.9 \%$ of TH-expressing neurons (179 of 206) were positive for GCaMP6s (Fig. 2D). These results suggest that GCaMP6s was mostly expressed in DA neurons. 
A

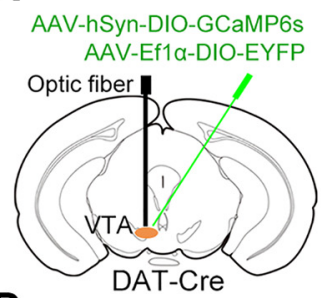

D

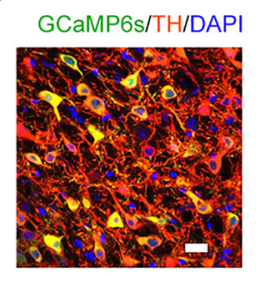

B

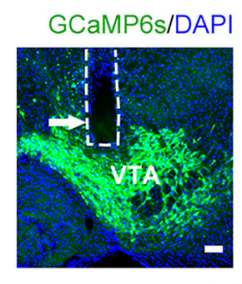

C

Bregma: $-3.16 \mathrm{~mm}$ Bregma: $-3.28 \mathrm{~mm}$ Bregma: $-3.52 \mathrm{~mm}$

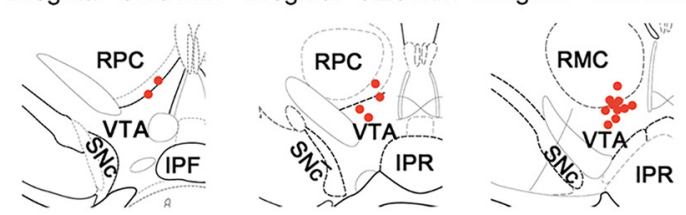

$\mathbf{F}$

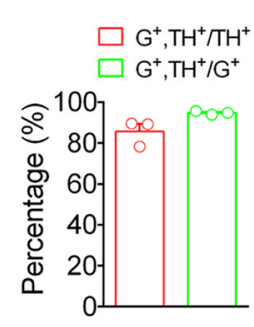

E
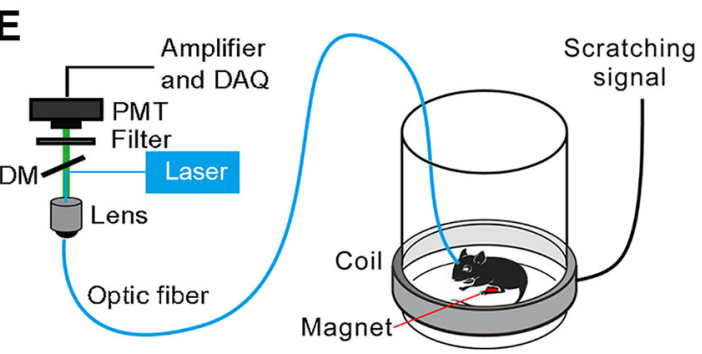

o Scratching events

$\times$ Other motion events

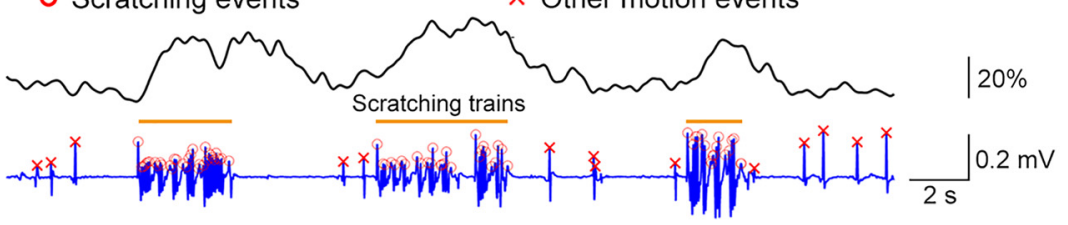

G
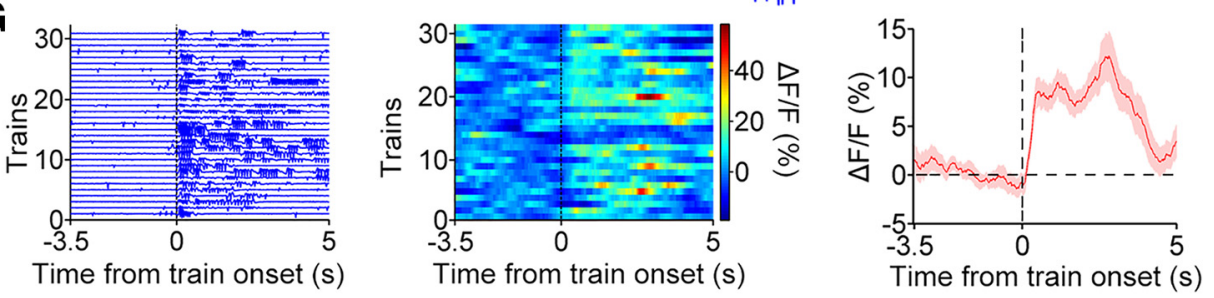

H

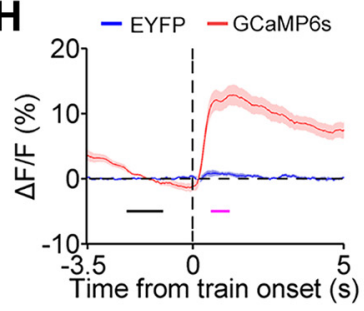

$\square$ EYFP $\square$ GCaMpos I
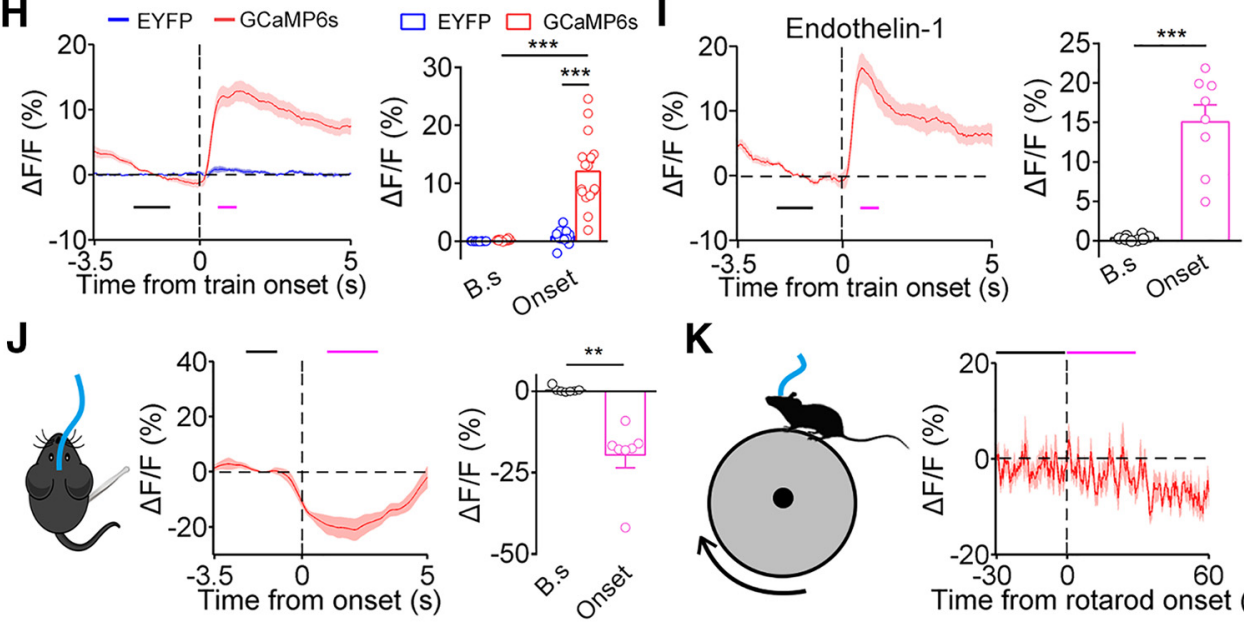

K
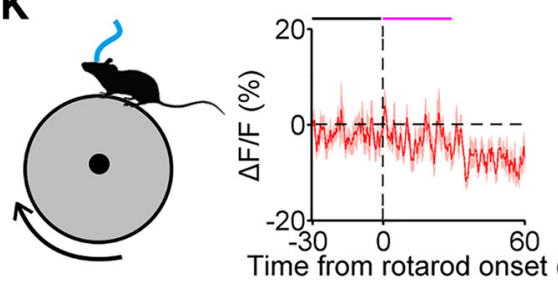

Time from rotarod onset (s)

Figure 2. Simultaneous fiber photometry and behavior recordings reveal a correlation between VTA DA neuronal activity and scratching behavior. $A$, Schematic of virus injection and optic fiber implantation. $\boldsymbol{B}$, Histological verification of the location of the optic fiber tip in a VTA ${ }^{\text {DA-GCaMP6s }}$ animal. The fiber-optic track is outlined by the dashed line. Scale bar, $100 \mu \mathrm{m}$. C, Distribution of the optic fiber tip locations in the mice used for the recording $(n=16)$. Labeled areas: red nucleus, parvicellular part (RPC); red nucleus, magnocellular part (RMC); interpeduncular fossa (IPF); interpeduncular nucleus, rostral subnucleus (IPR), substantia nigra pars compacta (SNc). D, Specificity of GCaMP6s expression. Left, Representative confocal image showing the expression of GCaMP6s and TH in the VTA. Scale bar, $20 \mu \mathrm{m}$. Right, Percentage of neurons labeled with GCaMP6s and TH (189 GCaMP6s ${ }^{+}$neurons and $206 \mathrm{TH}^{+}$neurons in 3 VTA ${ }^{\text {DA-GGaMP6s }}$ mice). $\mathrm{G}^{+}$, $\mathrm{GCaMPGS}^{+}$. E, Schematic of simultaneous recording of DA population activity by fiber photometry and scratching behavior. Data acquisition, DAQ. $F$, Representative DA fluorescence trace (top) and behavioral trace (bottom) recorded simultaneously in response to an intradermal injection of chloroquine. G, Activity of VTA DA neurons increased at the onset of a scratching train in a representative mouse. Left, Individual scratching train trace aligned to the onset. Middle, GCaMP6s fluorescence change during each corresponding scratching train. Right, Average fluorescence change. $\boldsymbol{H}$, Left, Average fluorescence change across the GCaMP6s group (red line; $n=16$ mice) and EYFP group (blue line; $n=13$ mice) in the chloroquine model. The black bar indicates the baseline period (B.S, -2.2 to $-1 \mathrm{~s}$ ) used to quantify the baseline fluorescence. The magenta bar indicates the scratching train onset period (Onset, $0.6-1.2 \mathrm{~s}$ ). Right, Quantification of average GCaMP6s and EYFP fluorescence change during the two periods (two-way ANOVA revealed group $\times$ period interaction; $F_{(1,53)}=38.80, p<0.001$; Bonferroni post hoc analysis, ${ }^{* * *} p<0.001$ ). $I$, Average fluorescence change in VTA ${ }^{\text {DA-GCaMPGs }}$ mice in the endothelin-1 model $\left(n=8 \mathrm{VTA}{ }^{\text {DA-GCaMP6s }}\right.$ mice; paired two-sided $t$ test, $t_{(7)}=7.12$, $\left.{ }^{* * *} p<0.001\right)$. J, DA population activity was inhibited by manually scratching the nape ( $n=7 \mathrm{VTA}{ }^{\text {DA-GCaMPGs }}$ mice; paired two-sided $t$ test, $t_{(6)}=4.79,{ }^{* *} p=0.003$ ). Baseline period (B.s), -2.2 to -1 s before the manual scratching. Onset period, $1-3$ s after the onset. $\boldsymbol{K}$, DA population did not show altered activity in response to motion on a rotarod ( $n=17 \mathrm{VTA} \mathrm{DA}^{\mathrm{DGCaMPGS}}$ mice; paired two-sided $t$ test, $\left.t_{(16)}=0.81, p=0.4308\right)$. Baseline period (B.s), -30 to $0 s$ before running onset. Running period, $0-30 \mathrm{~s}$ after the onset. The data are expressed as the mean \pm SEM. 

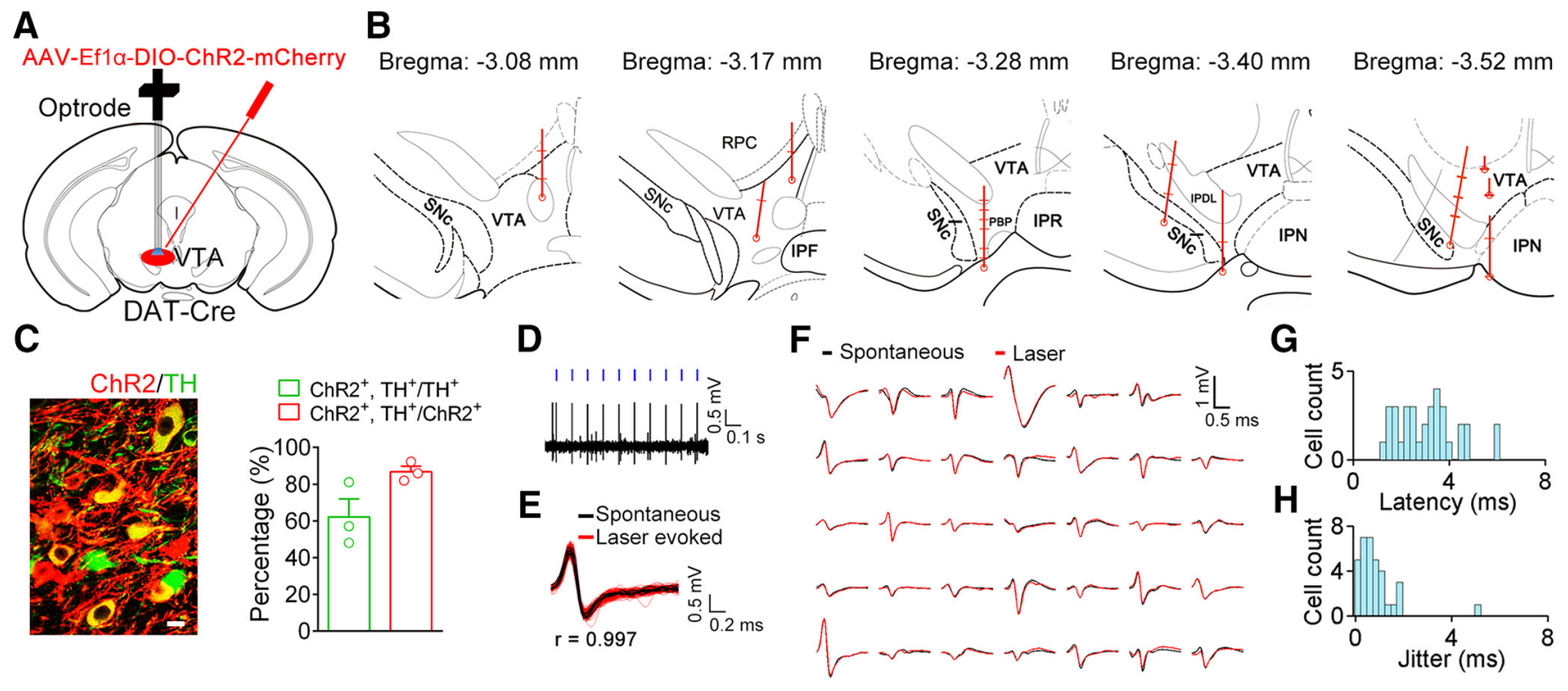

Figure 3. Opto-tagging of VTA DA neurons. $A$, Schematic of virus injection and optrode implantation. $B$, Reconstruction of the positions of the recorded DA neurons. Each circle represents a lesion center in an individual animal. Each horizontal line on the track indicates the estimated position of an identified DA neurons. Labeled areas: parabrachial pigmented nucleus of the VTA (PBP); red nucleus, parvicellular part (RPC); interpeduncular fossa (IPF); interpeduncular nucleus; rostral subnucleus (IPR); interpeduncular nucleus (IPN); interpeduncular nucleus, dorsolateral subnucleus (IPDL), substantia nigra pars compacta (SNc). C, Left, Representative confocal image showing the expression of ChR2 and TH in the VTA. Scale bar, $10 \mu \mathrm{m}$. Right, Percentage of neurons expressing ChR2 and TH. D, An example recording of spontaneous and laser-evoked spikes in a VTA neuron. Blue ticks, laser pulses ( $473 \mathrm{~nm}, 5 \mathrm{~ms})$. $\boldsymbol{E}$, Waveforms of all spontaneous (black) and laser-evoked (red) spikes in a representative neuron. $\boldsymbol{F}$, Average of spontaneous and light-induced waveforms (34 single units). $\boldsymbol{G}$, Histogram of the mean spike latency to light stimulation in 34 identified DA neurons. $\boldsymbol{H}$, Histogram of jitter of laser-evoked spike latency. The data are expressed as the mean \pm SEM.

Then, we sought to determine the correlation between the VTA DA population activity and scratching behavior by simultaneously recording calcium transients in VTA DA neurons with fiber photometry and mouse scratching behavior following an intradermal injection of chloroquine (Fig. 2E). The mouse scratching behavior was recorded using a magnetic induction method in which periodic voltage fluctuations were evoked by scratching (Inagaki et al., 2002; Mu et al., 2017). Scratching bouts and scratching trains were derived as described in Materials and Methods. We observed elevated GCaMP6s fluorescent signals during the scratching trains, indicating that the activity of VTA DA neurons increased during scratching behavior (Fig. 2F). By aligning the fluorescent signal to the scratching train onset, we found that the activity of DA neurons increased at the scratching train onset (Fig. 2G). To quantitatively measure the increase in the GCaMP6s signal following the scratching train onset, the following two time windows were defined: baseline window $(-2.2$ to $-1.0 \mathrm{~s}$ relative to onset); and the onset period (0.6-1.2 $\mathrm{s}$ relative to onset; Fig. $2 \mathrm{H}$, black and magenta bars). The analysis showed that the DA population exhibited significant activation during the onset period (Fig. $2 \mathrm{H}$ ). The change in the fluorescent signal in the VTA ${ }^{\text {DA-GCaMPos }}$ mice was not due to a movement artifact caused by the scratching behavior because the EYFP fluorescent change was negligible in the control animals (Fig. 2H). Consistent with the observations in the chloroquine model, the VTA DA neurons also exhibited increased activity during scratching behavior induced by an intradermal injection of endothelin-1 (Fig. 2I), which is an endogenous vasoconstrictor peptide that evokes an itch sensation in a histamine-independent manner (Sasaki and Hong, 1993).

The activation of DA neurons could be due to mechanical stimulation or scratching motion. To test these possibilities, we first recorded the activity of the VTA DA neuron population during a manual scratching of the nape test using metal tweezers.
We aligned the DA fluorescent signal to the onset of the mechanical stimulation and found that the DA neurons showed reduced response to the manual scratching (Fig. 2J). Subsequently, we investigated whether the activation of DA neurons during scratching was due to motion. We recorded the activity of VTA DA neurons in mice running on a rotarod and found no significant alteration in neural activity during the running motion (Fig. $2 K)$. These results suggest that the response of DA neurons during scratching was unlikely due to mechanical stimulation or motion associated with scratching.

\section{Dynamics of individual VTA DA neurons during itch-induced scratching behavior}

Although fiber photometry recordings are useful in examining population activity, these recordings reflect the sum of activity changes from nearby neurons and might mask the differential response of individual neurons (Adelsberger et al., 2005). To further examine the temporal dynamics of individual VTA DA neurons during itch-induced scratching behavior, we used the optogenetic tagging method to identify DA neurons during the extracellular recording (Cohen et al., 2012). A Cre-dependent AAV encoding ChR2 was injected into the VTA of DAT-Cre mice (Fig. 3A). We implanted homemade optrodes (electrode arrays with an optic fiber for light stimulation) into the virus injection area $\sim 3-4$ weeks after the viral infusion (Fig. 3B). We first quantified the specificity and efficiency of the expression of ChR2 in the VTA and found that $86.5 \%$ of neurons (141 of 163) expressing ChR2 were labeled with $\mathrm{TH}$ and that $58.5 \%$ of $\mathrm{TH}^{+}$neurons (141 of 241) expressed ChR2 (Fig. 3C), confirming the specificity of ChR2 expression. To optogenetically identify DA neurons during the extracellular recording, we delivered trains of light pulses (each train, $5 \mathrm{~ms}$ width) at 1,10 , or $20 \mathrm{~Hz}$, and the neural activity was simultaneously recorded. We found that neural spikes were induced during the light-pulse delivery period in some neurons 

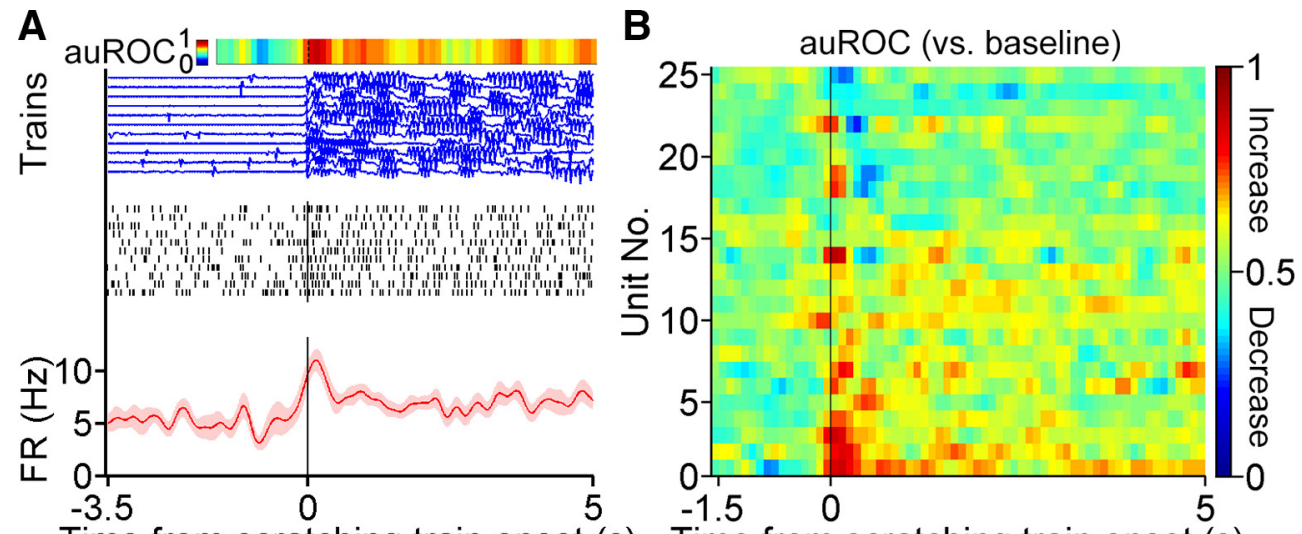

Time from scratching train onset (s) Time from scratching train onset (s)

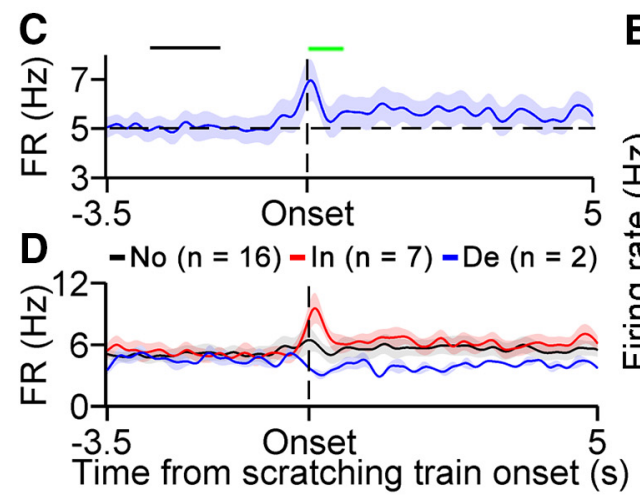

E

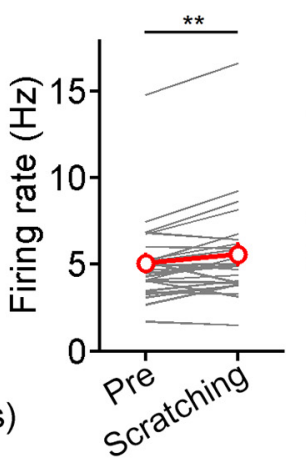

F

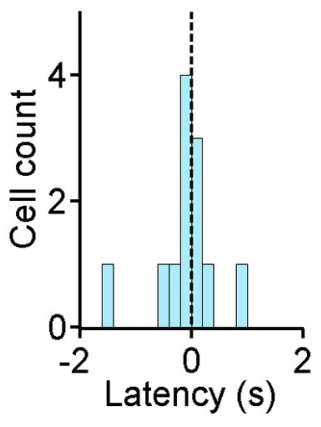

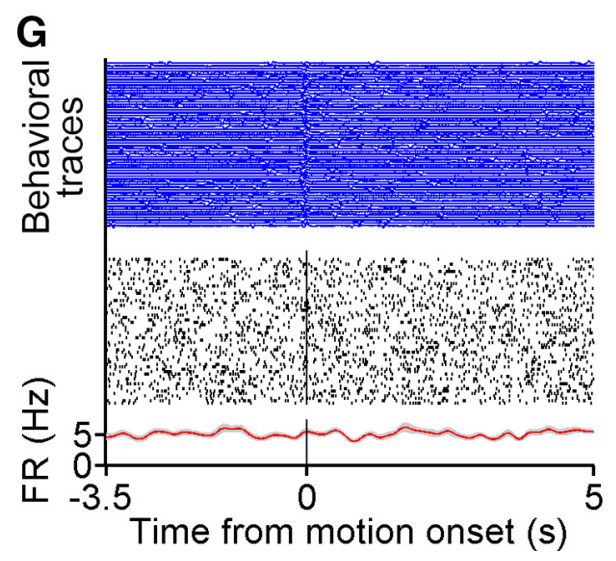

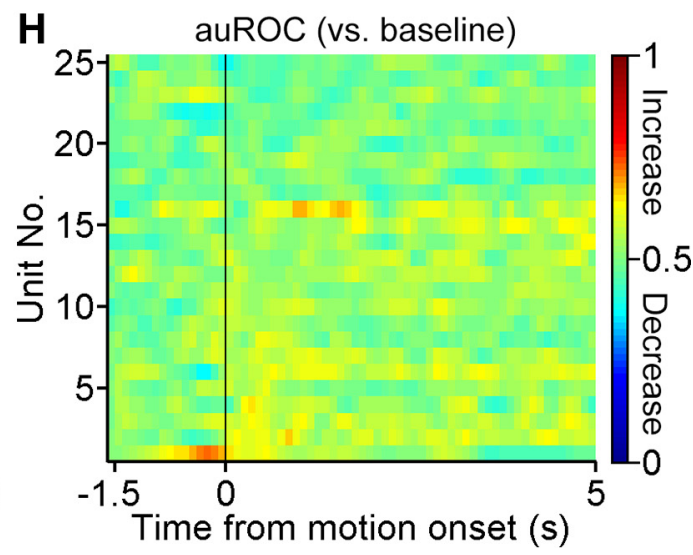

Figure 4. Dynamics of VTA DA neurons during chloroquine-induced scratching behavior. A, A representative DA neuron showing scratching-related activity. Top, Response profile as determined by the AUC ROC. Middle, Individual scratching train traces (blue) and spike raster (black ticks) during each corresponding scratching train. Bottom, Average firing rates. $\boldsymbol{B}$, Responses of DA neurons to scratching train onset ( -1.5 to $5 \mathrm{~s}$ ) as determined by the AUC ROC. C, Average firing rates of DA neurons near the scratching train onset ( -3.5 to $5 \mathrm{~s})$. The black bar indicates the baseline period $(-2.8$ to -1.6 s before scratching train onset), and the green bar represents the onset period ( $0-0.6 \mathrm{~s}$ after onset). $D$, Average firing rates of DA neurons showing significantly increased, decreased, or unchanged firing rates during a scratching train relative to the baseline period (paired two-sided $t$ test, $p<0.05$ for significance). No, No response; In, increased; De, decreased. $\boldsymbol{E}$, Average of the firing rate increase during scratching train periods relative to the baseline period (Pre; $n=25$ neurons; tw0-sided Wilcoxon matched-pairs signed rank test, ${ }^{* *} p=0.0067$ ). $F$, Response latency of significantly modulated neurons during the onset period. $\boldsymbol{G}$, Representative neuron showing no correlation between activity change and the onset of a motion event. $\boldsymbol{H}$, Responses of DA neurons to motion event onset ( -1.5 to $5 \mathrm{~s}$ ) during recording. The data are expressed as the mean \pm SEM. auROC, AUC ROC; FR, firing rate.

(Fig. 3D) and that the waveforms of the light-induced spikes were similar to those of the spontaneous spikes (Fig. $3 E, F$ ). The DA neurons were strictly identified by two criteria (see Materials and Methods). The optogenetically identified DA neurons showed a short latency and small jitter in the light-evoked response (Fig. $3 G, H)$, which are features suggestive of direct light-induced neuronal activation. In this experiment, we identified 34 putative DA neurons in the VTA $(3.4 \pm 1.0$ neurons/mouse; $n=10$ mice). Consistent with previous findings (Ungless and Grace, 2012), the baseline firing frequency of the identified VTA DA neurons is low (average baseline firing rate, $5.06 \pm 0.49 \mathrm{~Hz}$ ).
We simultaneously recorded the spiking activity of the optogenetically identified DA neurons and scratching behavior after an intradermal injection of chloroquine. Twenty-five optogenetically identified DA neurons showed stable recording and were included in the subsequent analysis. To examine the correlation between the activity of VTA DA neurons and itch-induced scratching behavior, we aligned the spiking activity to the onset of a scratching train (Fig. 4A). We observed that many DA neurons exhibited changes in activity (mainly excitation) near the onset (Fig. 4B). We averaged the firing rates of all recorded DA neurons near the scratching train onset ( -3.5 to $5 \mathrm{~s}$ ) and observed an 
increase in DA population activity near the onset (Fig. 4C). To further statistically analyze the response of DA neurons, we compared the firing rates of individual DA neurons during an entire scratching train with those during the baseline period $(-2.8$ to $-1.6 \mathrm{~s}$ before the scratching train onset). Of the 25 identified DA neurons, 7 neurons showed significantly increased activity during the scratching train, while 2 neurons showed significantly decreased activity (Fig. 4D). When pooled together, the activity of the DA neuron population was significantly increased (Fig. 4E). Considering the increase in DA neurons peaking early after onset, we also analyzed the neural response during the early scratching period (onset period, $0-0.6 \mathrm{~s}$; Fig. $4 C$, green bar) and found that nearly half of the identified DA neurons (12 of 25) showed a significant response. Among these responsive neurons, the majority (9 of 12) showed excitatory modulation. Interestingly, of the 12 DA neurons that showed a significant response during the onset period, more than half of these neurons (7 of 12) exhibited increased or decreased activity before the onset of the scratching train (Fig. $4 F$ ). The increase in the activity of the VTA DA neurons during scratching behavior is unlikely due to general motor activity as the activation of these neurons was rarely observed when the spiking activity was aligned to the onset of other motion events (Fig. 4G,H). In summary, the VTA DA neurons exhibited diverse responses to itch-induced scratching behavior, and a significant proportion of these neurons showed an elevated neural response.

\section{Photoinhibition of VTA DA neurons attenuated itch-induced scratching behavior}

As observed in both the fiber photometry and extracellular recording, the VTA DA neurons exhibited elevated neural activity during scratching behavior. Thus, we hypothesized that VTA DA neurons play an important role in modulating itch-induced scratching behavior. To test this hypothesis, we selectively suppressed VTA DA neurons after a scratching train onset with the optogenetic approach. We injected a Cre-dependent AAV encoding GtACR1, which is a light-gated anion channel (Govorunova et al., 2015), bilaterally into the VTA of DAT-Cre mice (Fig. $5 A, B)$, hereafter referred to as VTA ${ }^{\mathrm{DA}-G t \mathrm{ACR} 1}$ mice. The control group was injected with a Cre-dependent virus expressing EYFP (AAV-EF1 $\alpha$-DIO-EYFP), hereafter referred to as VTA ${ }^{\text {DA-EYFP }}$ mice. We first quantified the specificity and efficiency of the expression of GtACR 1 in the VTA and found that $99.8 \%$ of neurons (510 of 511) expressing GtACR1 were labeled with TH and that $88.9 \%$ of TH$^{+}$neurons ( 510 of 574) expressed GtACR1 (Fig. 5C), validating the specificity of GtACR1 expression. Then, we verified the efficiency of GtACR1 in suppressing the activity of DA neurons by recording GtACR1-EGFP ${ }^{+}$neurons in brain slices. The activity of the GtACR ${ }^{+}$neurons in the VTA was suppressed after light stimulation $(473 \mathrm{~nm} ; 24.9 \pm 4.5 \mathrm{~Hz}$ during baseline period vs $0 \pm 0 \mathrm{~Hz}$ during the light-on period; Wilcoxon matched-pairs signed rank test, $p=0.0313$; Fig. $5 D$ ). In contrast, light stimulation did not affect the firing of the EYFP ${ }^{+}$neurons $(473 \mathrm{~nm}$; $18.2 \pm 4.3 \mathrm{~Hz}$ during baseline period vs $16.4 \pm 4.1 \mathrm{~Hz}$ during light-on period; Wilcoxon matched-pairs signed rank test, $p=$ 0.0625; Fig. 5D). Therefore, photostimulation can efficiently suppress the activity of VTA neurons expressing GtACR1.

We implanted an optic fiber in the VTA for subsequent optogenetic manipulation during behavioral tests (Fig. $5 B, E$ ). To temporarily control the activity of DA neurons, we monitored the mouse behavior trace after an intradermal injection of chloroquine in real time. Light ( $473 \mathrm{~nm}$ for $3 \mathrm{~s} /$ delivery) was delivered manually after chloroquine-evoked scratching behavior was de- tected in both the EYFP and GtACR1 groups (Fig. 5F; for details, see Materials and Methods). The average delay of light delivery relative to the scratching train onset was within $1 \mathrm{~s}(0.99 \pm 0.03 \mathrm{~s}$ in the EYFP group vs $0.94 \pm 0.06 \mathrm{~s}$ in the GtACR1 group; Fig. $5 F$ ). The average intervals between adjacent light stimulation in a scratching train were $1.48 \pm 0.07$ and $0.91 \pm 0.06 \mathrm{~s}$ for the EYFP and GtACR1 groups, respectively. We found that the brief photoinhibition of VTA DA neurons significantly shortened the duration of the scratching train $(8.5 \pm 1.0 \mathrm{~s}$ in the EYFP group vs $4.4 \pm 0.5 \mathrm{~s}$ in the GtACR1 group; Fig. $5 G-I)$ and decreased the number of scratching trains (Fig. $5 J$ ). Moreover, the number of scratching bouts was also significantly decreased in the GtACR1 group compared with that in the EYFP group (scratching bout number: $156.0 \pm 30.5$ in the EYFP group vs $41.6 \pm 5.7$ in the GtACR1 group; Fig. $5 \mathrm{~K}$ ). In contrast, the duration of the scratching bouts was not affected by the photoinhibition of the VTA DA neurons (Fig. 5L).

To examine whether the decrease in the scratching train length was caused by nonspecific transient inhibition of VTA DA neurons, we next tested the effect of the pseudorandom inhibition of DA neurons on chloroquine-induced scratching behavior. We recorded the scratching behavior of VTA ${ }^{\text {DA-GtACR1 }}$ and VTA ${ }^{\text {DA-EYFP }}$ mice in pairs and delivered $473 \mathrm{~nm}$ of light $(3 \mathrm{~s} / \mathrm{stim}$ ulus) simultaneously to each pair of mice once the VTA ${ }^{\text {DA-EYFP }}$ mouse started to scratch (Fig. 5M). The light stimulation period overlapped with $<10 \%$ of the scratching train period in the $\mathrm{VTA}^{\mathrm{DA}-G t \mathrm{ACR} 1}$ mice $(7.5 \pm 1.3 \%$; Fig. $5 N)$. We found that the scratching behavior of the VTA ${ }^{\text {DA-GtACR1 }}$ mice was not significantly affected by the pseudorandom inhibition of VTA DA neurons as no significant difference was observed in the duration of the scratching trains (Fig. 5O,P) or the number of scratching trains (Fig. 5Q) between the two groups. Moreover, the number of scratching bouts (Fig. $5 R$ ) and the duration of the scratching bouts (Fig. $5 S$ ) were not significantly affected by the light stimulation. Subsequently, we investigated whether the transient inhibition of VTA DA neurons could affect general locomotor activity. Transient light (473 $\mathrm{nm}$ for $3 \mathrm{~s} /$ stimulus) was delivered at randomly chosen times during a 10 min open field test, and the same pattern was applied to all mice. We found that the brief suppression of VTA DA neurons did not significantly affect the locomotor activity of the VTA ${ }^{\text {DA-GtACR1 }}$ mice (Fig. 5T). Together, these results showed that the activity of VTA DA neurons is important for ongoing scratching behavior, suggesting that the DA system plays a modulating role in itch signal processing.

\section{Activity of dopaminergic fibers in the nucleus accumbens during itch processing}

Recent studies have revealed that VTA DA neurons are heterogeneous in both connectivity and function (Matsumoto and Hikosaka, 2009; Lammel et al., 2011; Roeper, 2013; Menegas et al., 2015; Morales and Margolis, 2017). The differential functions of DA subpopulations are mediated by different projections (Swanson, 1982; Yetnikoff et al., 2014; Saunders et al., 2018). Thus, we sought to identify the DA projections involved in the modulation of itch processing. The NAc receives DA input from the VTA and plays important roles in reward processing and motivated behavior (Björklund and Dunnett, 2007; Salamone and Correa, 2012; Hamid et al., 2016; Schultz, 2016). Thus, we explored the possible role of DA projections from the VTA to the NAc in itch modulation. To achieve this goal, we used fiber photometry to record the activity of DA fibers in the NAc. As different NAc subdivisions receive inputs from different subpopulations of VTA DA neurons and differently affect motivated behaviors (Aragona et al., 2008; 
A

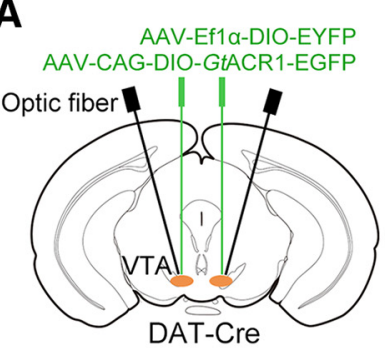

B

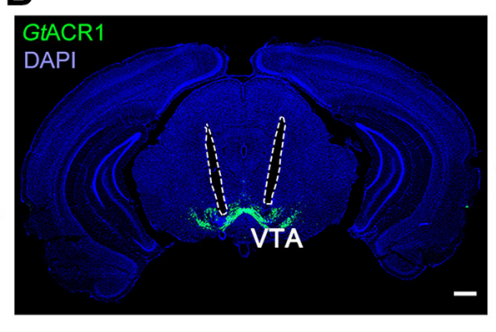

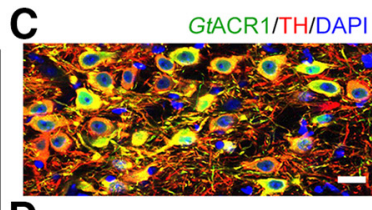

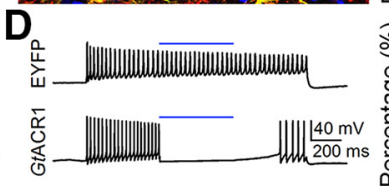

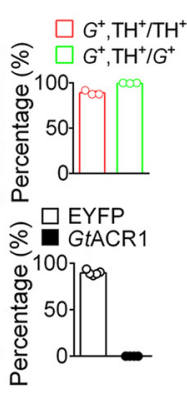

E

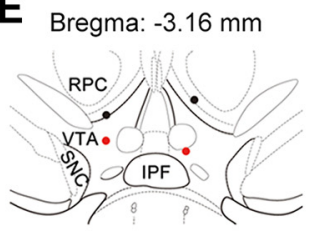

$\mathbf{F}$

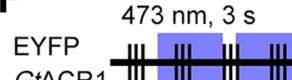

GLACR1

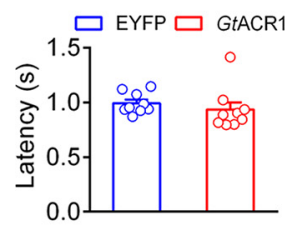

Bregma: $-3.40 \mathrm{~mm}$

Bregma: $-3.52 \mathrm{~mm}$

Bregma: $-3.64 \mathrm{~mm}$
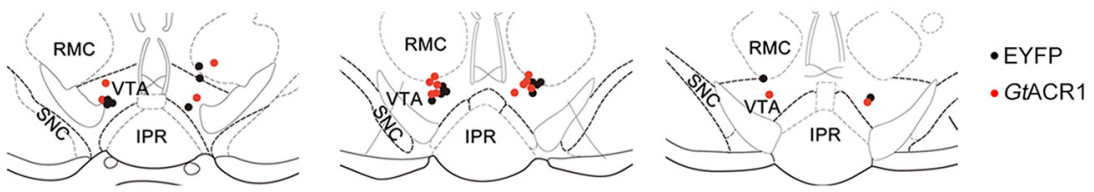

G

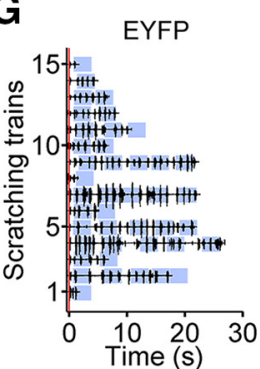

GtACR1

H

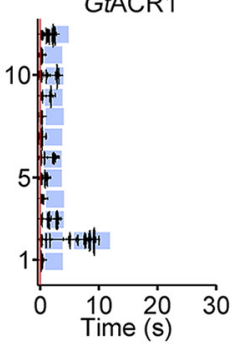

M
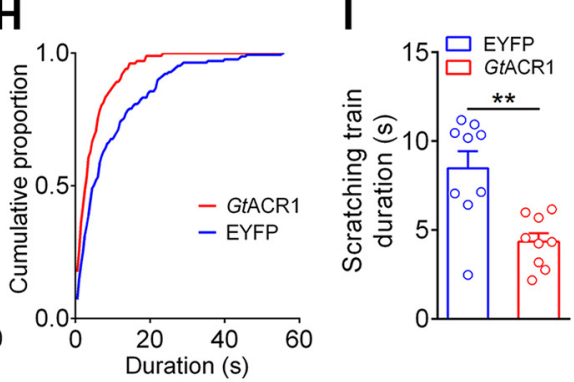

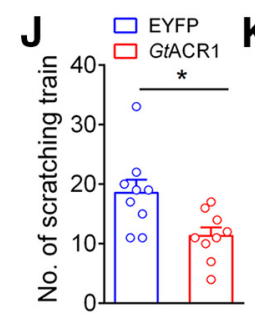

0

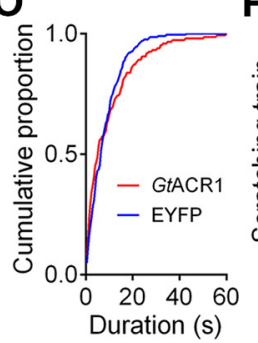

L

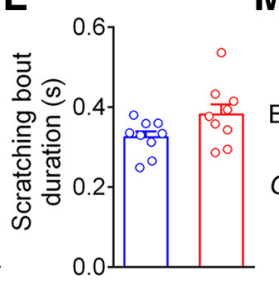

Q $\quad$ R

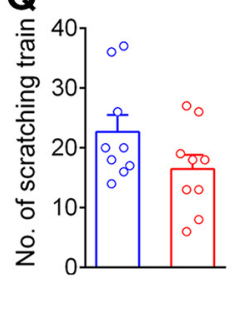

N

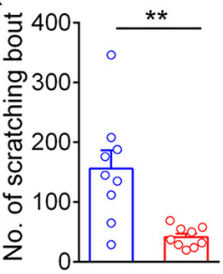

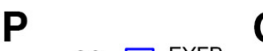

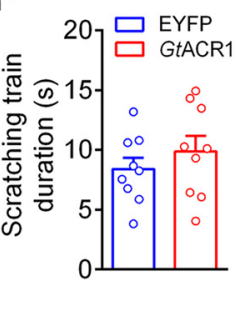

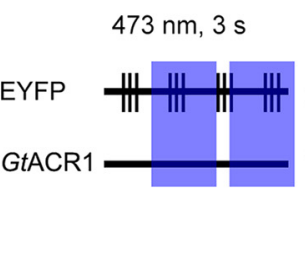

R

S $\quad T$

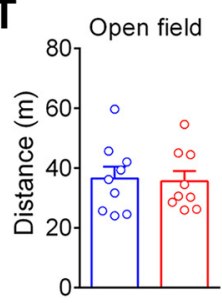

Figure 5. Optogenetic inhibition of VTA DA neurons attenuated chloroquine-induced scratching behavior. $\boldsymbol{A}$, Schematic of virus injection and optic fiber implantation. $\boldsymbol{B}$, Representative image illustrating GtACR1 expression and optic fiber track (outlined by dashed lines). Scale bar, $500 \mu \mathrm{m}$. C, Specificity of GtACR1 expression. Left, Representative confocal image showing the expression of GtACR1 and TH in the VTA. Scale bar, $20 \mu \mathrm{m}$. Right, Percentage of neurons labeled with GtACR1 and TH (511 GtACR1 ${ }^{+}$neurons and 574 TH $^{+}$neurons in 3 mice). $G^{+}, G t A C R 1{ }^{+}$.D, Left, Response of a representative EYFP ${ }^{+}$neuron (top) and a representative $G t A C R 1^{+}$neuron (bottom) to $473 \mathrm{~nm}$ light stimulation. Blue bars indicate $0.5 \mathrm{~s}$ of $473 \mathrm{~nm}$. Right, Percentage of the firing rates of neurons during the light-on period relative to the baseline period $\left(n=6 \mathrm{GACR}{ }^{+}\right.$neurons; $n=5 \mathrm{EYFP}{ }^{+}$neurons). $\boldsymbol{E}$, Histological verification of optic fiber tips. $\boldsymbol{F}$, Schematic showing transient light delivery to each VTA ${ }^{\text {DA-EYFP }}$ or VTA ${ }^{\text {DA-Gt ACR1 }}$ mouse after scratching onset. Top, Schematic of laser delivery pattern: vertical bar, scratching event; blue area, $3 \mathrm{~s}$ of $473 \mathrm{~nm}$ light delivery. Bottom,

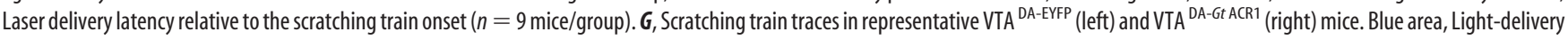
period; red line, onset of scratching train. $\boldsymbol{H}$, Cumulative proportion of the duration of scratching trains in the EYFP and GAACR1 groups. $\boldsymbol{I}$, Effect of the transient inhibition of DA neurons on scratching train duration (unpaired two-sided t test, $\left.t_{(16)}=3.81,{ }^{* *} p=0.0015\right)$. J, Total number of scratching trains was significantly decreased following the inhibition of DA neurons after the scratching onset (unpaired two-sided $t$ test, $t_{(16)}=2.77,{ }^{*} p=0.0136$ ). $\boldsymbol{K}$, Total number of scratching bouts was significantly decreased (unpaired two-sided $t$ test, $t_{(16)}=3.69$, $\left.{ }^{* *} p=0.002\right)$. $\boldsymbol{L}$, Average scratching bout duration was unaffected by the transient inhibition (unpaired two-sided $t$ test, $t_{(16)}=1.94, p=0.0697$ ). $M$, Schematic showing the pseudorandom transient light delivery to paired VTA ${ }^{\text {DA-EYPP }}$ and VTA ${ }^{\text {DA-Gt ACR1 }}$ mice after the VTA ${ }^{\text {DA-EYFP }}$ mice started to scratch. $N$, Raster plot of scratching bouts in a representative pair of VTA ${ }^{\text {DA-EYFP }}$ and VTA ${ }^{\text {DA-Gt ACR1 }}$ mice in a pseudorandom inhibition pattern. $\mathbf{O}$, Cumulative proportion of the duration of scratching trains in the EYFP and GtACR1 groups in a pseudorandom inhibition pattern. $\boldsymbol{P}$, Effect of pseudorandom transient inhibition of DA neurons on scratching train duration (unpaired two-sided $t$ test, $\left.t_{(16)}=0.94, p=0.3614\right)$. $\mathbf{Q}$, Total number of scratching trains did not significantly differ between the two groups following the pseudorandom transient inhibition (unpaired two-sided $t$ test, $t_{(16)}=1.67, p=0.1145$ ). $R$, Effect of pseudorandom transient inhibition of DA neurons on scratching bout number (unpaired two-sided $t$ test, $t_{(16)}=0.80, p=0.4378$ ). $S$, The average scratching bout duration did not significantly differ between the two groups following the pseudorandom transient inhibition (unpaired two-sided $t$ test, $t_{(16)}=0.63, p=0.5385$ ). $\boldsymbol{T}$, Transient inhibition of DA neurons by optogenetics did not change the traveled distance of the mice in an open field test ( $n=9$ mice/group; unpaired two-sided $t$ test, $\left.t_{(16)}=0.19, p=0.8535\right)$. The data are expressed as the mean \pm SEM. 
Lammel et al., 2008; Beier et al., 2015; Yang et al., 2018), we examined the activity of DA projection in the MeSh and LaSh of the NAc separately. We injected Cre-dependent virus expressing GCaMP6s unilaterally into the VTA of DAT-Cre mice and implanted optic fibers in two ipsilateral NAc subregions (Fig. 6AC). Dense GCaMP6s ${ }^{+}$axons were observed in the NAc (Fig. $6 B$ ). We found strong spontaneous fluctuations in fluorescence in both the NAc LaSh (Fig. 6D) and MeSh (Fig. 6E) 3 weeks after viral expression. Similar to the response detected in the VTA DA cell bodies (Fig. $2 F$ ), we found that the activity of DA fibers was correlated with chloroquine-induced scratching behavior in both the NAc LaSh (Fig. 6D) and MeSh (Fig. 6E). To test whether the DA projections in the LaSh and MeSh showed different responses to chloroquine-induced scratching, we quantitatively compared the activity changes in these two areas during the onset period. The DA fibers in the LaSh showed significantly higher activity increase during scratching behavior than those in the MeSh (Fig. $6 F, G)$. A similar response difference was observed during scratching behavior induced by endothelin-1 (Fig. $6 H, I$ ). Thus, these results suggest that the DA projection from the VTA to the NAc LaSh, rather than the MeSh, is strongly involved in the modulation of itch-induced scratching behavior.

\section{Discussion}

In this study, we showed that VTA DA neurons exhibited elevated neural activity correlated to itch-induced scratching behavior. The optogenetic suppression of VTA DA neurons attenuated itch-evoked scratching behavior. Additionally, the activity of DA fibers in the NAc LaSh recapitulated the activation of DA neurons in the VTA during scratching behavior. These results indicate that VTA DA neurons are critical for modulating itch information processing.

Our behavioral experiments indicate that the sustained activity of VTA DA neurons is required for itch-elicited scratching behavior. This finding is supported by data showing that the brief inhibition of VTA DA neurons during ongoing scratching behavior shortened the length of scratching trains and decreased the number of scratching trains. Our result is consistent with those of previous pharmacological experiments in which scratching behavior was modulated by manipulating both the $\mathrm{D}_{1}$ and $\mathrm{D}_{2}$ receptors (Rosenzweig-Lipson et al., 1994; Pellón et al., 1995; Akimoto and Furuse, 2011). Alternatively, this behavioral effect could have been due to motor deficits after the optogenetic inhibition of VTA DA neurons. However, we consider this possibility unlikely as the transient inhibition of DA neurons did not affect the locomotion of the mice in an open field test (Fig. 5T), which is consistent with the results reported in a previous study (Tan et al., 2012). Thus, our results suggest that VTA DA neurons play a critical role in the modulation of itch signal processing.

In both the fiber photometry recording and extracellular recording experiments, the DA neurons exhibited elevated activity changes in response to the itch-evoked scratching behavior. The activation of VTA DA neurons as measured by calcium imaging with fiber photometry was observed in both the chloroquine and endothelin-1 models (Fig. $2 \mathrm{H}, \mathrm{I}$ ). Consistently, we also obtained similar results when recording individual VTA DA neurons with the opto-tagging approach. In this experiment, we found that the average firing rates of the DA neurons started to increase before the beginning of scratching behavior and decreased as the scratching proceeded (Fig. 4C). The response timing observed in the VTA DA neurons differs from that of the response of itchsensitive spinothalamic tract neurons to scratching (Davidson et al., 2009), suggesting that DA neurons do not simply encode the sensory component of itchiness. The activation of the DA neuron population during scratching might reflect the pain sensation caused by mechanical input as previous studies have shown that aversive stimulation could activate some DA neurons in both anesthetized and awake animals (Brischoux et al., 2009; Matsumoto and Hikosaka, 2009; Zweifel et al., 2011). However, we consider this possibility unlikely because mechanical stimulation, which is similar to scratching, evoked a net inhibition of the DA population activity as measured by fiber photometry (Fig. $2 J)$. Additionally, the activation of VTA DA neurons was not simply due to motion as no increase in the activity of these neurons was observed when examining their response to the onset of running or moving (Fig. $2 K, 4 G, H$ ). Therefore, the activation of VTA DA neurons during scratching is correlated to itch-related signal processing.

Our results suggest that the activation of DA neurons near the onset of scratching behavior likely codes motivation driving subsequent scratching, which is supported by the fact that some DA neurons fired before scratching (Fig. $4 F$ ). This idea is consistent with the ability of DA neurons to process aversive and alerting signals (Bromberg-Martin et al., 2010), which, in turn, motivate behavioral consequences essential for survival. In addition, VTA DA neurons are implicated in encoding prediction error (Schultz, 2006), which is likely involved in the itch-scratching process as the VTA showed activity changes significantly correlated with scratching-induced pleasure in humans (Papoiu et al., 2013). The possibility that VTA DA neurons code prediction error during itch processing still remains to be examined. This would require the development of genetic tools and a behavioral paradigm that can precisely manipulate the itch circuit and the relief of itch (i.e., blocking the contact between the hindpaw and the nape randomly). Alternatively, as itchiness has a strong aversive nature, the activation of DA neurons could be the mix of the prediction error or motivation signal and the aversive aspect of itch, supported by the adaptive response of DA neurons in a context-dependent manner (Matsumoto et al., 2016). The paradigm used in our study could be used to further dissect the neural mechanism of aversion.

Notably, only a subpopulation of VTA DA neurons exhibited itch-related activity, and these neurons showed diverse response patterns. This result is consistent with those of previous studies demonstrating the functional heterogeneity of VTA DA neurons (Brischoux et al., 2009; Matsumoto and Hikosaka, 2009; Zweifel et al., 2011; Cohen et al., 2012). The diverse functions of DA neurons are thought to be mediated by their different projections (Lammel et al., 2011; Lammel et al., 2012; Beier et al., 2015; Menegas et al., 2015). The NAc is a major target of VTA DA neurons. The excitatory synapses on DA neurons projecting to the MeSh or LaSh of the NAc were differentially modulated after exposure to reward or aversive stimuli (Lammel et al., 2011). In our DA fiber activity recording experiment, we found that the DA fibers in the NAc showed strong activation during the onset of the itch-evoked scratching behavior. More importantly, the activation of the DA fibers in the NAc LaSh was significantly higher than that in the NAc MeSh (Fig. 6G,I), which is consistent with the notion that distinct subregions of the NAc are differentially involved in motivated behavior (Aragona et al., 2008; Berridge and Kringelbach, 2015; Yang et al., 2018). Previous studies have shown that the projection from VTA DA neurons to the NAc signals reward prediction error but not locomotion or novelty (Howe and Dombeck, 2016; Parker et al., 2016; Menegas et al., 2017). Therefore, the DA projection from the VTA to the NAc LaSh is likely involved in driving behavior for itch relief. 
A

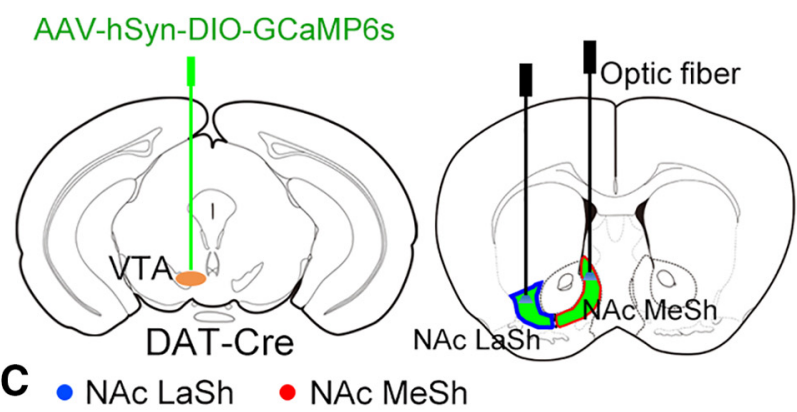

B
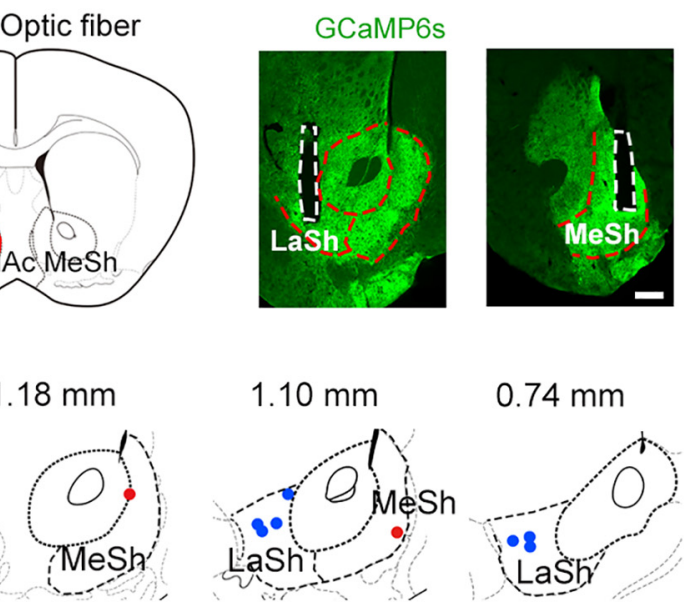

$1.10 \mathrm{~mm}$

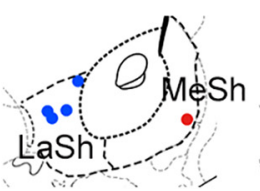

$0.74 \mathrm{~mm}$

D

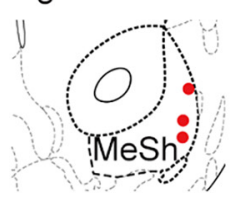

Scratching events $\times$ Other motion events

E
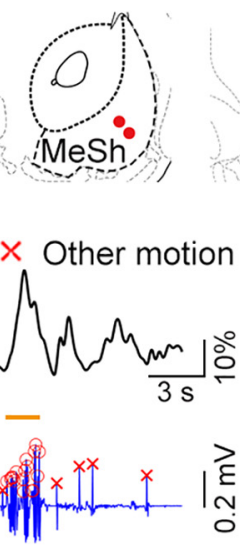

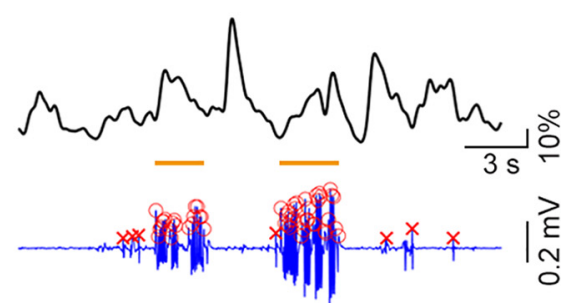

F

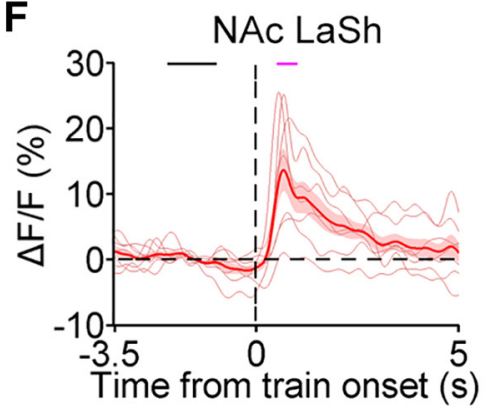

H

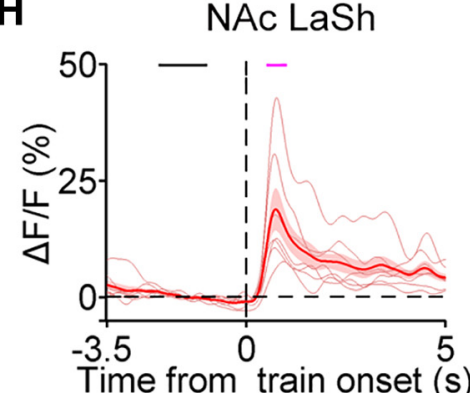

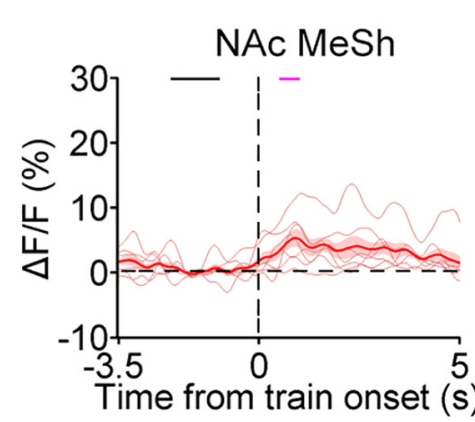

G Chloroquine

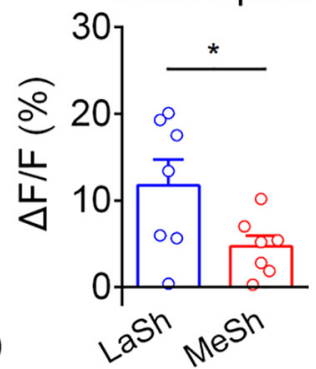

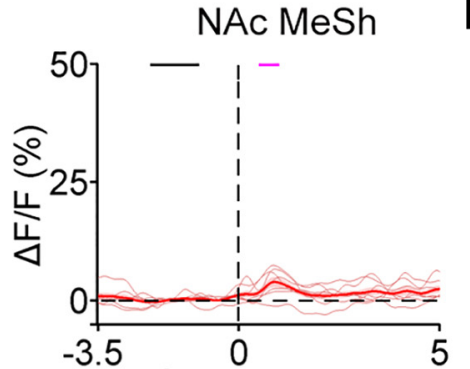

Time from train onset (s)

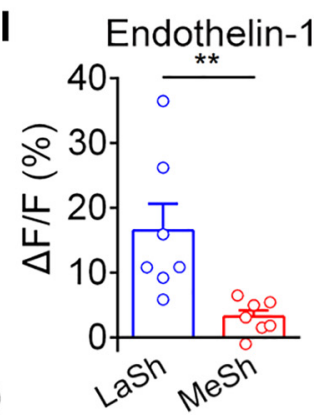

Figure 6. Activity of DA fibers in the NAc during itch-induced scratching behavior. $A$, Schematic of virus injection and optic fiber implantation for recording DA projection activity in the NAc with fiber photometry. B, GCaMP6s expression and representative fiber-optic tracks in each group. Scale bar, $300 \mu \mathrm{m}$. C, Histological verification of the location of optic fiber tips for all animals in the LaSh group $(n=7)$ and the MeSh group $(n=7)$. D, Representative DA projection fluorescence change in the NAc LaSh (top) and the behavioral trace (bottom) recorded simultaneously in response to an intradermal injection of chloroquine. $\boldsymbol{E}$, Representative DA projection fluorescence change in the NAc MeSh and the behavioral trace recorded simultaneously in response to an intradermal injection of chloroquine. $F$, Average fluorescence change in the LaSh group (left, $n=7$ mice) and in the MeSh group (right, $n=7$ mice) for the chloroquine model. The black bar indicates the baseline period $(-2.2$ to $-1 \mathrm{~s})$ used for the quantification analysis. The magenta bar indicates the scratching train onset period $(0.5-1 \mathrm{~s})$. G, Comparison of the average GCaMP6s fluorescence change between the two groups during the onset period in the chloroquine model (unpaired two-sided $t$ test, $\left.t_{(12)}=2.22,{ }^{*} p=0.0467\right)$. $\boldsymbol{H}$, Average fluorescence change in the LaSh (left) and the MeSh (right) groups for the endothelin-1 model ( $n=7$ mice in each group). $I$, Comparison of the average GCaMP6s fluorescence change between the two groups during the onset period in the endothelin-1 model (unpaired two-sided $t$ test, $t_{(12)}=3.11,{ }^{* *} p=0.009$ ). The data are expressed as the mean \pm SEM. 
The results of the fiber photometry and extracellular recording showed slight differences. The response of the population of VTA DA neurons observed in the fiber photometry recording was relatively slower than that in the extracellular recording (Fig. $2 \mathrm{H}, 4 \mathrm{C}$ ), which is likely due to the slow kinetics of GCaMP6s used in our experiments (Chen et al., 2013), highlighting the importance of analyzing the dynamics of DA neurons obtained via in vivo extracellular recording. Furthermore, we observed a continuous reduction in the population activity before the scratching onset in the fiber photometry recording (Fig. $2 \mathrm{H}$ ), which could occur because the elevated GCaMP6s signal in the DA neurons from previous scratching was not completely quenched, resulting in higher baseline activity before the scratching onset. An alternative explanation is that the recording sites differed as subpopulations of DA neurons in distinct locations encode different motivational signatures (Lammel et al., 2012). The tips of the optic fibers were mainly located above or inside the lateral VTA in the photometry recording (Fig. 2C), while the optogenetically identified DA neurons were scattered in the VTA (Fig. 3B). Finally, the change in DA neuron activity during scratching was compared with that during the defined baseline period before the scratching onset. We cannot rule out the possibility that DA neuron activity during the baseline period was already altered after the injection of pruritogens.

In summary, our study indicates that the DA neurons in the VTA play an important modulatory role in itch signal processing. DA neurons projecting to the lateral shell of the NAc might play a major role in itch modulation. These results extend our understanding of the circuit mechanism underlying the regulation of itch processing by the neuromodulatory system. Knowledge regarding the circuit mechanisms underlying itch modulation could shed light on treatments for chronic itch.

\section{References}

Adelsberger H, Garaschuk O, Konnerth A (2005) Cortical calcium waves in resting newborn mice. Nat Neurosci 8:988-990. CrossRef Medline

Akimoto Y, Furuse M (2011) SCH23390, a dopamine D1 receptor antagonist, suppressed scratching behavior induced by compound 48/80 in mice. Eur J Pharmacol 670:162-167. CrossRef Medline

Aragona BJ, Cleaveland NA, Stuber GD, Day JJ, Carelli RM, Wightman RM (2008) Preferential enhancement of dopamine transmission within the nucleus accumbens shell by cocaine is attributable to a direct increase in phasic dopamine release events. J Neurosci 28:8821-8831. CrossRef Medline

Beier KT, Steinberg EE, DeLoach KE, Xie S, Miyamichi K, Schwarz L, Gao XJ, Kremer EJ, Malenka RC, Luo L (2015) Circuit architecture of VTA dopamine neurons revealed by systematic input-output mapping. Cell 162: 622-634. CrossRef Medline

Berridge KC, Kringelbach ML (2015) Pleasure systems in the brain. Neuron 86:646-664. CrossRef Medline

Björklund A, Dunnett SB (2007) Dopamine neuron systems in the brain: an update. Trends Neurosci 30:194-202. CrossRef Medline

Brischoux F, Chakraborty S, Brierley DI, Ungless MA (2009) Phasic excitation of dopamine neurons in ventral VTA by noxious stimuli. Proc Natl Acad Sci U S A 106:4894-4899. CrossRef Medline

Bromberg-Martin ES, Matsumoto M, Hikosaka O (2010) Dopamine in motivational control: rewarding, aversive, and alerting. Neuron 68:815-834. CrossRef Medline

Cetin A, Komai S, Eliava M, Seeburg PH, Osten P (2006) Stereotaxic gene delivery in the rodent brain. Nat Protoc 1:3166-3173. CrossRef Medline

Chen TW, Wardill TJ, Sun Y, Pulver SR, Renninger SL, Baohan A, Schreiter ER, Kerr RA, Orger MB, Jayaraman V, Looger LL, Svoboda K, Kim DS (2013) Ultrasensitive fluorescent proteins for imaging neuronal activity. Nature 499:295-300. CrossRef Medline

Cohen JY, Haesler S, Vong L, Lowell BB, Uchida N (2012) Neuron-typespecific signals for reward and punishment in the ventral tegmental area. Nature 482:85-88. CrossRef Medline
Davidson S, Zhang X, Khasabov SG, Simone DA, Giesler GJ Jr (2009) Relief of itch by scratching: state-dependent inhibition of primate spinothalamic tract neurons. Nat Neurosci 12:544-546. CrossRef Medline

Dong X, Dong X (2018) Peripheral and central mechanisms of itch. Neuron 98:482-494. CrossRef Medline

Gotoh Y, Andoh T, Kuraishi Y (2011a) Noradrenergic regulation of itch transmission in the spinal cord mediated by alpha-adrenoceptors. Neuropharmacology 61:825-831. CrossRef Medline

Gotoh Y, Omori Y, Andoh T, Kuraishi Y (2011b) Tonic inhibition of allergic itch signaling by the descending noradrenergic system in mice. J Pharmacol Sci 115:417-420. CrossRef Medline

Govorunova EG, Sineshchekov OA, Janz R, Liu X, Spudich JL (2015) Natural light-gated anion channels: a family of microbial rhodopsins for advanced optogenetics. Science 349:647-650. CrossRef Medline

Gunaydin LA, Grosenick L, Finkelstein JC, Kauvar IV, Fenno LE, Adhikari A, Lammel S, Mirzabekov JJ, Airan RD, Zalocusky KA, Tye KM, Anikeeva P, Malenka RC, Deisseroth K (2014) Natural neural projection dynamics underlying social behavior. Cell 157:1535-1551. CrossRef Medline

Hamid AA, Pettibone JR, Mabrouk OS, Hetrick VL, Schmidt R, Vander Weele CM, Kennedy RT, Aragona BJ, Berke JD (2016) Mesolimbic dopamine signals the value of work. Nat Neurosci 19:117-126. CrossRef Medline

Harris KD, Hirase H, Leinekugel X, Henze DA, Buzsáki G (2001) Temporal interaction between single spikes and complex spike bursts in hippocampal pyramidal cells. Neuron 32:141-149. CrossRef Medline

Harris-Warrick RM, Marder E (1991) Modulation of neural networks for behavior. Annu Rev Neurosci 14:39-57. CrossRef Medline

Herde L, Forster C, Strupf M, Handwerker HO (2007) Itch induced by a novel method leads to limbic deactivations a functional MRI study. J Neurophysiol 98:2347-2356. CrossRef Medline

Howe MW, Dombeck DA (2016) Rapid signalling in distinct dopaminergic axons during locomotion and reward. Nature 535:505-510. CrossRef Medline

Inagaki $\mathrm{N}$, Igeta $\mathrm{K}$, Kim JF, Nagao $\mathrm{M}$, Shiraishi $\mathrm{N}$, Nakamura N, Nagai $\mathrm{H}$ (2002) Involvement of unique mechanisms in the induction of scratching behavior in BALB/c mice by compound 48/80. Eur J Pharmacol 448: 175-183. CrossRef Medline

Kupfermann I (1979) Modulatory actions of neurotransmitters. Annu Rev Neurosci 2:447-465. CrossRef Medline

Lammel S, Hetzel A, Häckel O, Jones I, Liss B, Roeper J (2008) Unique properties of mesoprefrontal neurons within a dual mesocorticolimbic dopamine system. Neuron 57:760-773. CrossRef Medline

Lammel S, Ion DI, Roeper J, Malenka RC (2011) Projection-specific modulation of dopamine neuron synapses by aversive and rewarding stimuli. Neuron 70:855-862. CrossRef Medline

Lammel S, Lim BK, Ran C, Huang KW, Betley MJ, Tye KM, Deisseroth K, Malenka RC (2012) Input-specific control of reward and aversion in the ventral tegmental area. Nature 491:212-217. CrossRef Medline

Leknes SG, Bantick S, Willis CM, Wilkinson JD, Wise RG, Tracey I (2007) Itch and motivation to scratch: an investigation of the central and peripheral correlates of allergen- and histamine-induced itch in humans. J Neurophysiol 97:415-422. CrossRef Medline

Liu D, Gu X, Zhu J, Zhang X, Han Z, Yan W, Cheng Q, Hao J, Fan H, Hou R, Chen Z, Chen Y, Li CT (2014) Medial prefrontal activity during delay period contributes to learning of a working memory task. Science 346 : 458-463. CrossRef Medline

Lu YC, Wang YJ, Lu B, Chen M, Zheng P, Liu JG (2018) ACC to dorsal medial striatum inputs modulate histaminergic itch sensation. J Neurosci 38:3823-3839. CrossRef Medline

Matsumoto H, Tian J, Uchida N, Watabe-Uchida M (2016) Midbrain dopamine neurons signal aversion in a reward-context-dependent manner. eLife 5:e17328. CrossRef Medline

Matsumoto M, Hikosaka O (2009) Two types of dopamine neuron distinctly convey positive and negative motivational signals. Nature 459: 837-841. CrossRef Medline

Menegas W, Bergan JF, Ogawa SK, Isogai Y, Umadevi Venkataraju K, Osten P, Uchida N, Watabe-Uchida M (2015) Dopamine neurons projecting to the posterior striatum form an anatomically distinct subclass. eLife 4:e10032. CrossRef Medline

Menegas W, Babayan BM, Uchida N, Watabe-Uchida M (2017) Opposite initialization to novel cues in dopamine signaling in ventral and posterior striatum in mice. eLife 6:e21886. CrossRef Medline 
Morales M, Margolis EB (2017) Ventral tegmental area: cellular heterogeneity, connectivity and behaviour. Nat Rev Neurosci 18:73-85. CrossRef Medline

Mu D, Deng J, Liu KF, Wu ZY, Shi YF, Guo WM, Mao QQ, Liu XJ, Li H, Sun YG (2017) A central neural circuit for itch sensation. Science 357:695699. CrossRef Medline

Navratilova E, Atcherley CW, Porreca F (2015) Brain circuits encoding reward from pain relief. Trends Neurosci 38:741-750. CrossRef Medline

Papoiu AD, Nattkemper LA, Sanders KM, Kraft RA, Chan YH, Coghill RC, Yosipovitch G (2013) Brain's reward circuits mediate itch relief. A functional MRI study of active scratching. PLoS One 8:e82389. CrossRef Medline

Parker NF, Cameron CM, Taliaferro JP, Lee J, Choi JY, Davidson TJ, Daw ND, Witten IB (2016) Reward and choice encoding in terminals of midbrain dopamine neurons depends on striatal target. Nat Neurosci 19:845854. CrossRef Medline

Pellón R, Flores P, Alling K, Witkin JM, Katz JL (1995) Pharmacological analysis of the scratching produced by dopamine D2 agonists in squirrel monkeys. J Pharmacol Exp Ther 273:138-145. Medline

Pi HJ, Hangya B, Kvitsiani D, Sanders JI, Huang ZJ, Kepecs A (2013) Cortical interneurons that specialize in disinhibitory control. Nature 503: 521-524. CrossRef Medline

Roeper J (2013) Dissecting the diversity of midbrain dopamine neurons. Trends Neurosci 36:336-342. CrossRef Medline

Rosenzweig-Lipson S, Hesterberg P, Bergman J (1994) Observational studies of dopamine D1 and D2 agonists in squirrel monkeys. Psychopharmacology 116:9-18. CrossRef Medline

Salamone JD, Correa M (2012) The mysterious motivational functions of mesolimbic dopamine. Neuron 76:470-485. CrossRef Medline

Sasaki T, Hong MH (1993) Localization of endothelin-1 in the osteoclast. J Electron Microsc (Tokyo) 42:193-196. Medline

Saunders BT, Richard JM, Margolis EB, Janak PH (2018) Dopamine neurons create Pavlovian conditioned stimuli with circuit-defined motivational properties. Nat Neurosci 21:1072-1083. CrossRef Medline

Schmitzer-Torbert N, Jackson J, Henze D, Harris K, Redish AD (2005) Quantitative measures of cluster quality for use in extracellular recordings. Neuroscience 131:1-11. CrossRef Medline

Schultz W (2006) Behavioral theories and the neurophysiology of reward. Annu Rev Psychol 57:87-115. CrossRef Medline

Schultz W (2016) Dopamine reward prediction-error signalling: a twocomponent response. Nat Rev Neurosci 17:183-195. CrossRef Medline
Schultz W, Dayan P, Montague PR (1997) A neural substrate of prediction and reward. Science 275:1593-1599. CrossRef Medline

Swanson LW (1982) The projections of the ventral tegmental area and adjacent regions: a combined fluorescent retrograde tracer and immunofluorescence study in the rat. Brain Res Bull 9:321-353. CrossRef Medline

Tan KR, Yvon C, Turiault M, Mirzabekov JJ, Doehner J, Labouèbe G, Deisseroth K, Tye KM, Lüscher C (2012) GABA neurons of the VTA drive conditioned place aversion. Neuron 73:1173-1183. CrossRef Medline

Tye KM, Mirzabekov JJ, Warden MR, Ferenczi EA, Tsai HC, Finkelstein J, Kim SY, Adhikari A, Thompson KR, Andalman AS, Gunaydin LA, Witten IB, Deisseroth K (2013) Dopamine neurons modulate neural encoding and expression of depression-related behaviour. Nature 493:537-541. CrossRef Medline

Ungless MA, Grace AA (2012) Are you or aren't you? challenges associated with physiologically identifying dopamine neurons. Trends Neurosci 35: 422-430. CrossRef Medline

Yang H, de Jong JW, Tak Y, Peck J, Bateup HS, Lammel S (2018) Nucleus accumbens subnuclei regulate motivated behavior via direct inhibition and disinhibition of VTA dopamine subpopulations. Neuron 97:434449.e4. CrossRef Medline

Yetnikoff L, Lavezzi HN, Reichard RA, Zahm DS (2014) An update on the connections of the ventral mesencephalic dopaminergic complex. Neuroscience 282:23-48. CrossRef Medline

Yu YQ, Barry DM, Hao Y, Liu XT, Chen ZF (2017) Molecular and neural basis of contagious itch behavior in mice. Science 355:1072-1076. CrossRef Medline

Zhao ZQ, Liu XY, Jeffry J, Karunarathne WK, Li JL, Munanairi A, Zhou XY, Li H, Sun YG, Wan L, Wu ZY, Kim S, Huo FQ, Mo P, Barry DM, Zhang CK, Kim JY, Gautam N, Renner KJ, Li YQ, et al (2014) Descending control of itch transmission by the serotonergic system via 5-HT1A-facilitated GRPGRPR signaling. Neuron 84:821-834. CrossRef Medline

Zhou L, Liu MZ, Li Q, Deng J, Mu D, Sun YG (2017) Organization of functional long-range circuits controlling the activity of serotonergic neurons in the dorsal raphe nucleus. Cell Rep 20:1991-1993. CrossRef Medline

Zweifel LS, Fadok JP, Argilli E, Garelick MG, Jones GL, Dickerson TM, Allen JM, Mizumori SJ, Bonci A, Palmiter RD (2011) Activation of dopamine neurons is critical for aversive conditioning and prevention of generalized anxiety. Nat Neurosci 14:620-626. CrossRef Medline 